\title{
Carbon footprint in building distributed energy system: an optimization-based feasibility analysis for potential emission reduction
}

\author{
Yamin Yan ${ }^{1}$, Haoran Zhang ${ }^{*, 2}$, Jing Meng ${ }^{3}$, Yin Long ${ }^{* *, 4}$, Xingyuan Zhou ${ }^{1}$, Zhouchao Li ${ }^{1}$, Yufei \\ Wang ${ }^{5}$, Yongtu Liang ${ }^{1}$ \\ 1 Beijing Key Laboratory of Urban Oil and Gas Distribution Technology, China University of \\ Petroleum-Beijing, Fuxue Road No. 18, Changping District, Beijing 102249, China; \\ 2 Center for Spatial Information Science, The University of Tokyo, 5-1-5 Kashiwanoha, Kashiwa, \\ Chiba 277-8563, Japan; \\ 3 The Bartlett School of Construction and Project Management, University College London, London \\ WC1E 7HB, UK \\ 4 Department of Environment Systems, Graduate School of Frontier Sciences, The University of \\ Tokyo, 5-1-5 Kashiwanoha, Kashiwa-shi, Chiba 277-8563, Japan. \\ 5 State Key Laboratory of Heavy Oil Processing, China University of Petroleum-Beijing, Fuxue \\ Road No. 18, Changping District, Beijing, 102249, PR China \\ ${ }^{*}$ Corresponding author: E-mail address: zhang ronan@csis.u-tokyo.ac.jp (H. Zhang); \\ long@globalenv.k.u-tokyo.ac.jp (Y. Long)
}

\begin{abstract}
Buildings account for more than one-third of the global primary energy consumption and are responsible for most of the global greenhouse gas emission. As one of the infrastructures of buildings, energy systems are crucial to control overall energy consumption and associated emissions. Despite much consideration on improving the efficiency of buildings energy system and the utilization of renewable energy, there has been little discussion on the carbon footprint quantification of building distributed energy systems as well as the reduction potentiality. In such a context, this paper proposed a life cycle economic and carbon emissions assessment framework by dividing the building distributed energy system into five stages. Subsequently, a multiobjective mathematical model is developed with minimal life cycle cost and carbon footprint, while respecting energy balance and technical constraints, and the optimal energy system and the carbon footprint distribution are obtained by solving the model. Finally, a case study is conducted on the building energy system design in a district in Xuzhou to test the effectiveness of this method. The correlation between optimal energy system carbon footprint by facility attributes, and the distribution of energy system carbon footprint by stage and source are investigated. It's found that the carbon emissions in the operation and maintenance stage accounts for the largest share in the entire life cycle. In addition, the proportion of carbon emissions from natural gas is the highest, accounting for $65-73 \%$ under environmental optimization and $85-88 \%$ under economic optimization. Followed by electricity, with a share of $26-34 \%$ and $10-14 \%$ under environmental and economic optimization, respectively. Finally, a sensitivity analysis is carried out to analyze the impact of energy carbon emission factors.
\end{abstract}

Keywords: Building distributed energy system; Life cycle assessment; Carbon footprint; Multiobjective mathematical programming; Sensitivity analysis 


\section{Introduction}

The urban areas with large building density occupy about 32\% of global primary energy consumption (Edenhofer and Seyboth, 2013). In China, buildings account for more than $30 \%$ of total primary energy consumption (He et al., 2014), accompanied by a large amount of carbon emissions, which are still increasing in recent years. In such a context, it is necessary to develop the distributed energy system (DES) that can effectively integrate multiple sustainable energy sources to satisfy the high demand of energy (Anastaselos et al., 2016). Compared with traditional concentrated and large-scaled energy system, DES can facilitate to mitigate the crisis and realize sustainable development with the advantages of energy saving (Gao et al., 2018), environment protection (Khan et al., 2019; Padmanathan et al., 2019) and high safe performance (Khan et al., 2018). With the support of government policies and the promotion of financial incentives (Akorede et al., 2010), hundreds of DES projects have been built in China from 2010 to 2015, and the penetration of DES in buildings is expected to continue to increase in the future (Zhang et al., 2018). Therefore, as the target of the largest reduction allocation, the buildings energy system requires a specific analysis to explore its impact on the overall carbon footprint mitigation plan.

In previous studies, a lot of scholars have focused on the carbon footprint schemes of building, including commercial buildings (Acha et al., 2018), federal buildings, educational buildings, and households (Sharma et al., 2011). With the development of clean development mechanism (CDM), quantitative carbon emission accounting has become a research hotspot. To include the carbon emission from cradle to grave, life cycle assessment (LCA) has been used widely to analyze the carbon emissions of buildings. For instance, Nematchoua et al. (2019) carried out a meticulous statistical analysis of the buildings life cycle and identified the main elements that affect the environment during the construction, operation, renovation, and demolition stages of buildings. Results show that the energy consumption in operation stage has the largest contribution to greenhouse gas (GHG) emissions. Other literatures also focused on the building carbon emissions in various countries, such as China (Zhu et al., 2019), Australia (Robati et al., 2019), South Korea (Sim and Sim, 2016), and Norway (Wrålsen et al., 2018). In the abovementioned studies, scholars mainly focused on the buildings carbon footprint analysis, and each project has its own characteristics, such as end-users' demand and location, which have a direct impact on the carbon emissions of buildings (Fenner et al., 2018).

In addition to a large number of life cycle analysis of building carbon footprint, previous studies also discussed the building energy system which mainly focus on the improvement on efficiency of energy systems ( $\mathrm{K}$ et al., 2017) and the utilization of renewable energy (Anastas and Zimmerman, 2003; Yan et al., 2019) . For instance, Somma et al. (2017) proposed a multi-objective mathematical programming (MOMP) model to minimize the total cost and maximize overall exergy efficiency of DESs simultaneously. By using branch-and-cut algorithm, the Pareto solutions are obtained and the total annual cost is reduced by 21-36\%. Li et al. (2017) focused on the operation optimization in terms of economy and environment, considering the energy balance constraints and the minimum performance factor indicator are obtained by using the algorithm. In the abovementioned studies, the selection of device and energy allocation schemes were obtained by establishing and solving the optimization model. However, the research on carbon emissions of 
building energy system is limited to the energy consumption statistics and simulations during the operational stage, and several indirect emissions sources that may represent a big share of the carbon footprint of building energy system, such as the production of raw materials, are often overlooked by most studies.

In fact, the carbon footprint analysis of building energy system is of great importance for defining the distribution of carbon emissions in the life cycle of energy systems and guiding energy conservation and emission reduction. With the support of carbon accounting method and carbon emission quantitative indicators of building energy system, policy makers could make a scientific and reasonable evaluation of the impact of building energy system on the environment, and then select energy system with superior performance (Fournier et al., 2019). A carbon emission framework for building energy system is still under development, but should provide enough information to identify carbon sources of carbon emissions, thus providing scientific evidence for emission reduction schemes. In addition, from the viewpoint of life cycle, the optimization work of building energy system can be conducted to obtain the optimal design and operation schemes while achieving the goals of minimal life cycle cost and carbon emissions.

In order to fill the research gap, this paper first introduces the quantitative cost and carbon footprint accounting approach of building energy system based on the life cycle theory, and then establishes a MOMP model to obtain the optimal energy allocation schemes, design and operation schemes of DES while minimizing the life cycle cost and carbon emissions. This method is able to obtain the cost-effective energy system with the best life cycle performance, and it's performed in the planning of the DES for building clusters in the district in the city of Xuzhou, in Jiangsu Province in eastern China. The optimal clusters and DES configuration, correlation between DES carbon footprint by facility attributes, and the distribution of DES carbon footprint by stage and source are presented and discussed. Some recommendations are put forward for the planning and design of DES as well.

The innovations and contributions of this study are summarized as follows:

(1) For the first time, this paper develops a quantitative life cycle cost and carbon emissions accounting framework for DES. The proposed method can provide designers with guidance on cost and carbon footprint analysis of building energy system.

(2) A MOMP model is established while minimizing the life cycle cost and carbon emissions of DES for building clusters. By solving the model, the optimal design and operation schemes as well as carbon footprint distribution of DES could be obtained.

(3) The correlation between DES carbon footprint by facility attributes, and the distribution of carbon footprint by stage and source are presented. The results can provide a better understanding of the contribution of facilities, energy sources, and various stages to the carbon footprint distribution of DES, and provide critical policy insights for future DES.

(4) A sensitivity analysis is carried out to study the effect of various natural gas and electricity carbon emission factors on the life cycle cost and carbon footprint of DES.

This paper proceeds as follows. Firstly, the structure of DES in the district and the problem are described in Section 2. Then, Section 3 gives a framework of life cycle cost and carbon footprint accounting method, and describes the multi-objective mathematical model and the solution method in detail. Subsequently, the final results solved by the proposed model and the 
corresponding discussions are presented and analyzed in Section 4. Finally, Section 5 concludes this paper and provides policy implications.

\section{Problem description}

Fig 1 shows the structure of a distributed energy system (DES) that installed in each building cluster in the district, including the ground-source heat pump (GSHP), gas boiler (GB), gas-fired CHP engine (CHP), biomass boiler (BIO), compression chiller (COC), absorption chiller (ABC), PV panels (PV), battery (BT), heating storage (HS) and cooling storage (CS). Generally, the electricity demand is satisfied by the power grid, and the deficiency can be supplied by PV panels if installed. As to the cooling demand, it can be served by the power grid using compression chillers or by the waste-heat from gas boiler using absorption chillers. There are four categories of facilities to meet heating demand, consisting of GB, CHP, BIO, and GSHP. The energy storage equipment plays a vital role in peak shaving.

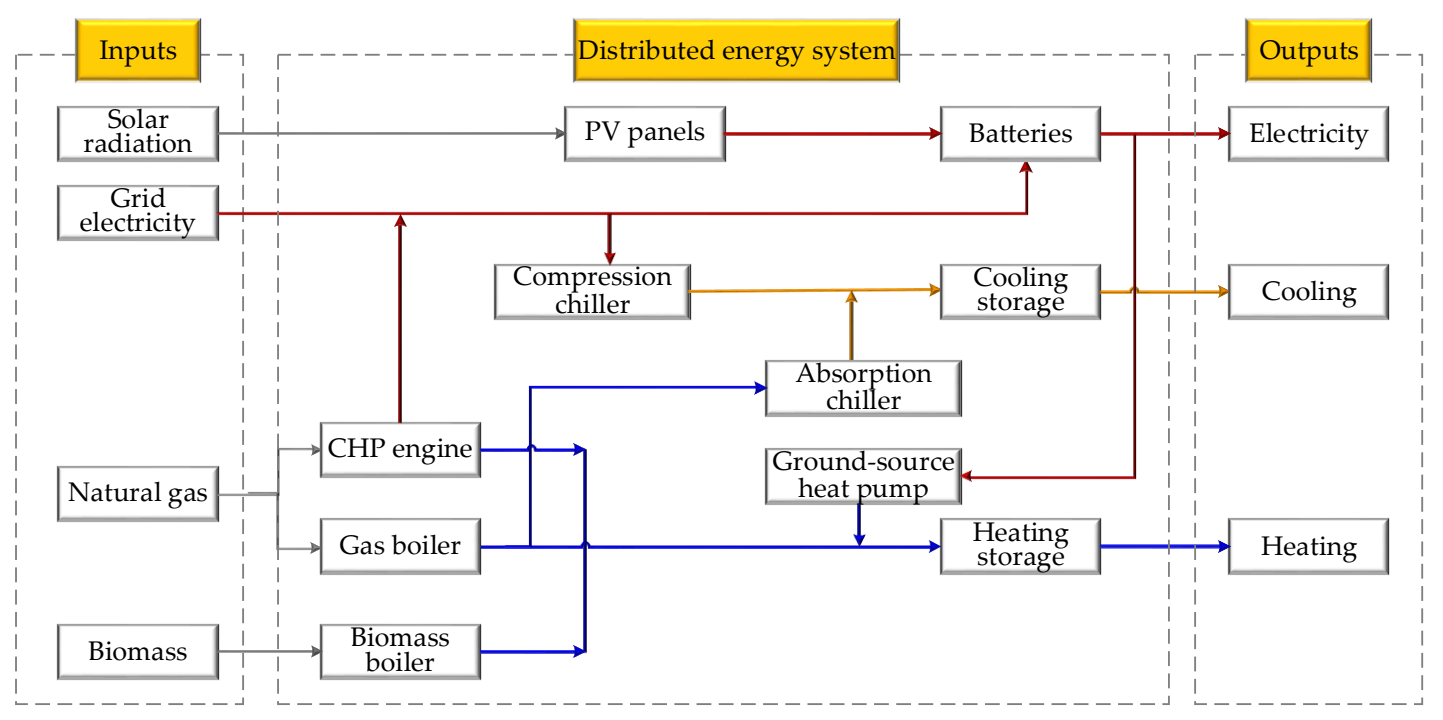

Figure 1. Structure of DES for each building cluster in the district.

In the DES project, the district is divided into $N$ building clusters according to the maximum installation capacity of DES, and each building cluster is considered to install one DES. Fig. 2 shows the framework of the optimization process, which consists of four parts: (1) Parameter inputs, (2) Life cycle accounting approach, (3) MOMP model, (4) Results and discussions. In the first part, basic information should be prepared, consisting of energy demand, weather and cost information, and technical and emission inputs. In the second part, the detail life cycle cost and carbon emissions accounting approach is given by dividing the energy system life cycle into five stages: predevelopment and consenting stage, product stage, installation and commissioning stage, operation and maintenance stage, and decommissioning and disposal stage. In the third part, a MOMP model is set up to optimize the cluster and design of district buildings with DES taking the life cycle cost and carbon emissions as the objectives. Finally, the Pareto frontier is obtained by solving the model, and the economic performance and carbon footprint distribution under five stages are analyzed. 

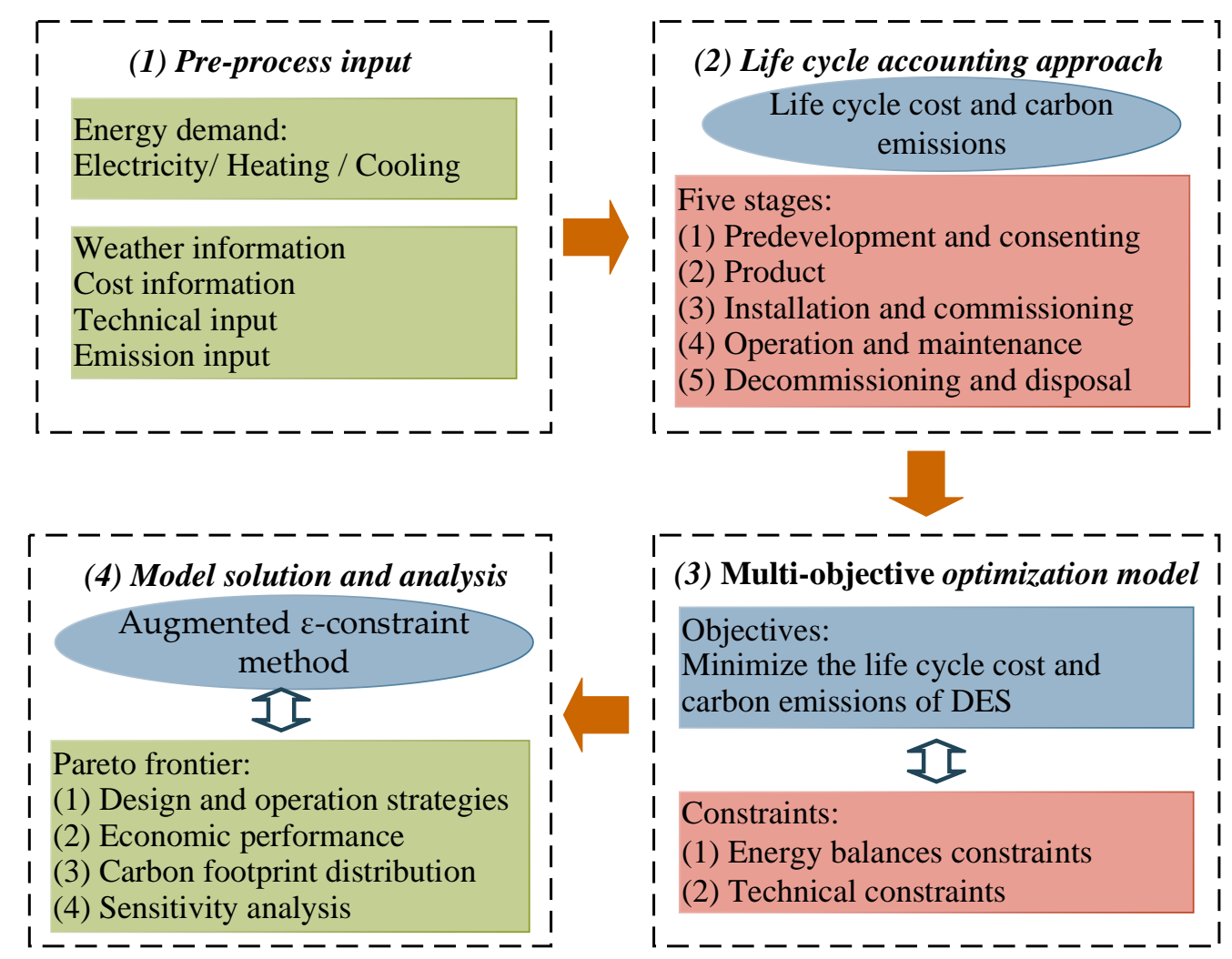

Figure 2. The overview of the optimization process

\section{Methodology}

\subsection{Life cycle cost and carbon footprint accounting approach}

Based on the theory of life cycle assessment (LCA), we carried out the cost and carbon footprint analysis of DES by dividing the energy system life cycle into five stages: predevelopment and consenting stage, product stage, installation and commissioning stage, operation and maintenance stage, and decommissioning and disposal stage (Fig.3). The following sections describe the calculation model of cost and carbon emissions (CCE) in each DES life-cycle stage.

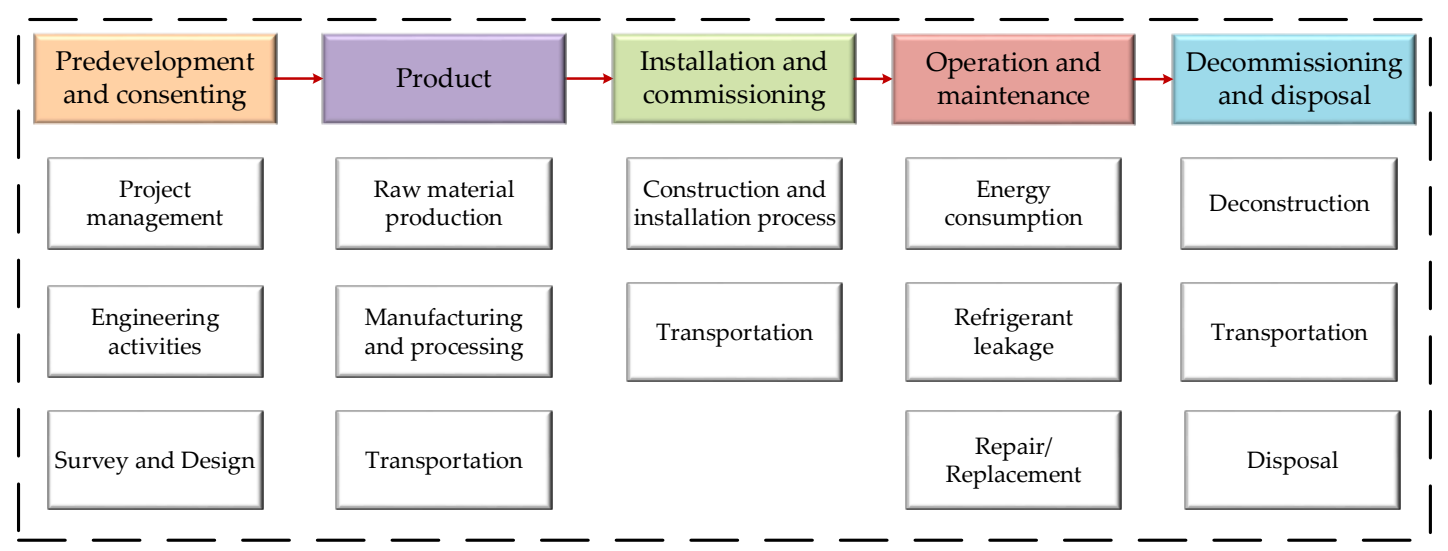

Figure 3. System framework of life cycle cost and carbon emissions of DES. 


\subsubsection{Predevelopment and consenting stage}

In the predevelopment and consenting stage, many researchers participated in the project and experienced the overall preparation, framework selection, system demonstration, and protocol preparation. The predevelopment and consenting cost $C_{P \& C}$ mainly include project management cost $C_{\text {proju }}$, engineering activities cost $C_{\text {eng }}$, and survey and design cost $C_{\text {sur \& des }}$, which is defined as shown in Eq. (1). The predevelopment and consenting carbon emission $E_{P \& C}$ is generated by the researchers during the survey, which are related to the transportation distance and transportation mode.

$$
\begin{gathered}
C_{P \& C}=C_{\text {projM }}+C_{\text {eng }}+C_{\text {sur \&des }} \\
E_{P \& C}=\sum_{t r} L_{t r} F_{t r} \lambda_{t r} N_{t r}
\end{gathered}
$$

Where $L_{t r}$ is the transportation distance of transportation mode $t r,[\mathrm{~km}] ; F_{t r}$ defines the energy consumption of transportation mode $t r$ per person per kilometer, $[\mathrm{MJ} / \mathrm{pp} . \mathrm{km}] ; \lambda_{t r}$ is the carbon emissions generated by the unit fuel used for transportation mode $t r,[\mathrm{~kg} / \mathrm{MJ}] ; N_{t r}$ defines the number of researchers using transportation mode $t r,[-]$.

\subsubsection{Product stage}

The product stage cost $C_{\text {pro }}$ is equal to the facility investment cost, which is defined as shown in Eq. (3).

$$
\begin{gathered}
C_{p r o}=\sum_{n \in N} \sum_{i \in I}\left(B_{n, i} C_{i}^{f i x}+W_{n, i} C_{i}^{\text {linear }}\right) A_{i} \\
A_{i}=\frac{r(r+1)^{L t_{i}}}{(r+1)^{L t_{i}}-1}
\end{gathered}
$$

where $C_{f a c}$ refers to the investment cost of facility which will be introduced in detail in section 3.1.4, [CHF]; $N$ is the number of building clusters, [-]; $B_{n, i}$ represents the installation of facility $i$ for $n$ cluster, [-]; $W_{n, i}$ represents the capacity of facility $i$ for $n$ cluster, [kW, kWh, $\left.\mathrm{m}^{2}\right] ; C_{i}^{f i x}$ represent the fixed investment cost, $[\mathrm{CHF}] ; C_{i}^{\text {linear }}$ defines the capacity-dependent cost of facility $i,\left[\mathrm{CHF} / \mathrm{kW}, \mathrm{CHF} / \mathrm{kWh}, \mathrm{CHF} / \mathrm{m}^{2}\right]$; The capital recovery factor of facility $A_{i}$, used to annualize the cost of a facility, as shown in Eq. (4), [-]; $r$ is the discount rate, [-]; $L t_{i}$ refers to the lifetime of facility $i$, [year].

The contribution of carbon emissions in the product stage includes the raw material production, manufacturing and processing, and transportation (Chau et al., 2015), and it's calculated by the emission intensity of the unit raw materials. Considering the loss in the production process of the facility and the recyclability of the recyclable materials, the total carbon emissions are calculated according to Eq. (5).

$$
E_{p r o}=\sum_{i} \sum_{r}\left(1+\varepsilon_{r}\right)\left[Q_{i, r} E F_{c r}\left(1-\delta_{r}\right)+Q_{i, r} E F_{c r}^{r m} \delta_{r}\right]+\sum_{i} Q_{i} E l e_{i} E F_{\text {grid }}
$$

where $E_{\text {pro }}$ is the total carbon emissions of facility during the product stage, $[\mathrm{kg}] ; \varepsilon_{r}$ is the waste coefficient of raw material $r$ due to loss during the production process, [-]; $Q_{i, r}$ the mass or 
volume of raw material $r$ used in facility $i,[\mathrm{~kg}, \mathrm{~m} 3] ; E F_{c r}$ and $E F_{c r}^{r m}$ represent the emission intensity of a unit mass or volume of raw material $r$ during the production and recycling process, $\left[\mathrm{kg} / \mathrm{kg}, \mathrm{kg} / \mathrm{m}^{3}\right] ; \delta_{r}$ defines the recovery coefficient of raw material $r,[-] ; E l e_{i}$ represents the electrical energy consumed by the unit mass of facility $i$ during secondary processing, $[\mathrm{kWh} / \mathrm{kg}]$; $E F_{\text {grid }}$ denotes the emission factor of electricity, $[\mathrm{kg} / \mathrm{kWh}]$.

\subsubsection{Installation and commissioning stage}

The installation and commissioning stage costs $C_{\text {ins scom }}$ refer to the costs incurred by the manufacturer in assembling the facility and conducting trial production to ensure the normal operation of facility, including material consumption, power consumption, manual consumption, etc., which are generally $6 \%-8 \%$ of the basic price of the facility.

$$
C_{\text {ins\&com }}=\psi C_{f a c}
$$

The carbon emission sources during the installation and commissioning stage mainly include two aspects: the first one $E_{c t}$ comes from the mechanical energy consumption to transport the facility from the manufacturer to the construction site, the second carbon emission source $E_{c e}$ derives from the facility installation technology in the engine-room and heat exchange station. The total carbon emissions $E_{\text {insecom }}$ in the installation and commissioning stage are defined as follows.

$$
\begin{gathered}
E_{\text {ins\&com }}=E_{c t}+E_{c e} \\
E_{c t}=\sum_{t r} \sum_{i} Q_{i} L_{i, t r} F_{i, t r} \lambda_{t r} \\
E_{c e}=\sum_{y} R_{y}^{\text {install }} H_{y}^{\text {install }} \lambda_{y}^{\text {install }}
\end{gathered}
$$

Where $L_{i, t r}$ is the transportation distance of facility $i$ under transportation mode $t r,[\mathrm{~km}]$; $F_{i, t r}$ defines the unit turnover energy consumption of facility $i$ under transportation mode $t r$, $[\mathrm{MJ} / \mathrm{kg} . \mathrm{km}] ; \lambda_{t r}$ is the carbon emissions generated by the unit fuel used for transportation mode $t r,[\mathrm{~kg} / \mathrm{MJ}] ; R_{y}^{\text {install }}$ represent the engineering quantity of installation technology $y$ in the engineroom or heat exchange station, [-]; $H_{y}^{\text {isstall }}$ denotes the energy consumption per unit of engineering quantity of installation technology $y,[\mathrm{MJ}] ; \lambda_{y}^{\text {install }}$ is the carbon emissions generated by the unit fuel used for installation technology $y,[\mathrm{~kg} / \mathrm{MJ}]$.

\subsubsection{Operation and maintenance stage}

The operation and maintenance stage cost $C_{\text {ope\&ma }}$ consists of facility maintenance cost $C_{m a}$, and energy consumption cost $C_{\text {Ene }}$, which is defined as shown in Eq. (10). Notably, the energy expenditure $C_{E n e}$ is equal to the annual energy expenditure multiplied by operating period $T_{\text {ope\&ma }}$ , and the facility maintenance costs are calculated in the same way.

$$
\begin{gathered}
C_{\text {ope\&ma }}=C_{\text {Ene }}+C_{m a} \\
C_{\text {Ene }}=T_{\text {ope\&ma }} \sum_{n \in N} \sum_{t \in T} \sum_{m \in M} C P_{n, t, m} P_{t, m} w_{t} \\
C_{m a}=T_{\text {ope\&ma }} \sum_{n \in N} \sum_{i \in I} \sum_{t \in T} O M_{n, i} R_{n, i, t} w_{t}
\end{gathered}
$$


$T_{\text {ope\&ma }}$ defines the system operation period, [year]; $C P_{n, t, m}$ represents the consumption of energy $m$ at time step $t$ in $n$ cluster, [kWh]; $P_{t, m}$ represents the price of energy $m$ at time step $t,[\mathrm{CHF} / \mathrm{kWh}] ; w_{t}$ defines the number of time step $t,[-] ; O M_{n, i}$ is the operation and maintenance cost of the facility $i$ in $n$ cluster, $\left[\mathrm{CHF} / \mathrm{kW}, \mathrm{CHF} / \mathrm{kWh}, \mathrm{CHF} / \mathrm{m}^{2}\right] ; R_{n, i, t}$ is the energy rate provided by the facility $i$ at time step $t$ in $n$ cluster, [kW, $\left.\mathrm{kWh}, \mathrm{m}^{2}\right]$.

The operation and maintenance stage carbon emissions $E_{\text {ope\&ma }}$ mainly come from energy consumption during the system operation phase and refrigerant leakage during the system maintenance phase. The calculation formula is shown as follows:

$$
E_{\text {ope\&ma }}=T_{\text {ope\&ma }} \sum_{m} C P_{n, t, m} E F_{m} w_{t}+T_{\text {ope\&ma }} \sum_{\text {rel }} D_{\text {rel }} \alpha_{r e l}
$$

where $C P_{n, t, m}$ represents the annual consumption of energy $m$ at time step $t$ in $n$ cluster, $[\mathrm{kWh}] ; E F_{m}$ denotes the carbon emission factor of energy $m,[\mathrm{~kg} / \mathrm{kWh}] ; D_{\text {rel }}$ defines the annual amount of refrigerant leakage $r e l,[\mathrm{~kg}] ; \alpha_{r e l}$ is the climate change potential of refrigerant $r e l$, $[\mathrm{kgCO} / \mathrm{kg}]$.

\subsubsection{Decommissioning and disposal stage}

The materials used in DES are basically recyclable materials, and their recycling costs have been considered in the product stage and are not included here. Therefore, the decommissioning and disposal stage cost $C_{D \& D}$ mainly includes the dismantling and transportation cost of system facility.

$$
C_{D \& D}=C_{\text {disposal }}+C_{\text {trans }}
$$

The carbon emissions $E_{D \& D}$ are mainly derived from the demolition and transportation of waste facility. The specific calculation formula is defined as follows:

$$
E_{D \& D}=\sum_{i} R_{i}^{d i s} H_{i}^{d i s} \lambda_{i}^{d i s}+\sum_{t y} \sum_{i} Q_{i} L_{i, t r} F_{i, t r} \lambda_{t r}
$$

Where $R_{i}^{d i s}$ represent the disposal engineering quantity of facility $i$ in the engine-room or heat exchange station, $[-] ; H_{i}^{\text {dis }}$ denotes the energy consumption per unit of disposal engineering quantity of facility $i,[\mathrm{MJ}] ; \lambda_{i}^{\text {dis }}$ is the carbon emissions generated by the unit fuel used for demolishing facility $i,[\mathrm{~kg} / \mathrm{MJ}]$.

\subsection{Mathematical Model}

\subsubsection{Economic Objective}

The economic objective value $C_{L C C}$ is the life cycle cost of the DES project, including the predevelopment and consenting cost $C_{P \& C}$, the product stage cost $C_{p r o}$, the installation and commissioning stage costs $C_{\text {ins \&com }}$, the operation and maintenance stage cost $C_{\text {ope\&ma }}$, and the decommissioning and disposal stage cost $C_{D \& D}$, which is described as follows:

$$
C_{L C C}=C_{P \& C}+C_{\text {pro }}+C_{\text {ins\&com }}+C_{\text {ope\&ma }}+C_{D \& D}
$$

\subsubsection{Environmental Objective}

Similarly, the environmental objective value $E_{L C C}$ is the life cycle carbon emissions of the DES project, including the predevelopment and consenting carbon emissions $E_{P \& C}$, the product stage 
carbon emissions $E_{\text {pro }}$, the installation and commissioning stage carbon emissions $E_{\text {ins \&com }}$, the operation and maintenance stage carbon emissions $E_{\text {ope\&ma }}$, and the decommissioning and disposal stage carbon emissions $E_{D \& D}$, which is described as follows:

$$
E_{L C C}=E_{P \& C}+E_{\text {pro }}+E_{\text {ins\&com }}+E_{\text {ope\&ma }}+E_{D \& D}
$$

\subsubsection{Energy Balance Constraints}

Notably, the energy balance constraints are developed for the operation and maintenance stage of the DES project, and it's able to facilitate the realization of co-ordination of supply and demand for electricity, heating, and cooling. These constraints aim to satisfy the energy demands of each building in the district (Mavromatidis et al., 2018). Specifically, Eq. (18) indicates that the electricity demand is satisfied by the electricity from grid, PV panels, and CHP engines minus the electricity consumed by COC and GSHP. Regarding to the cooling energy demand, which is shown in Eq. (19), is satisfied by COC and ABC. Eq. (20) indicates that the heating demand is met by GB, $\mathrm{CHP}, \mathrm{BIO}$, and GSHP.

$$
\begin{gathered}
M_{n, t, g r i d}+n_{P V} W_{n, P V} I N_{t}^{P V}+n_{C H P, e l e} M_{n, t, C H P}-M_{n, t, C O C}-M_{n, t, G S H P}+N_{n, t, B T}^{d i s}-N_{n, t, B T}^{c h}=\sum_{u \in U} X_{n, u} D_{u, t}^{\text {elec }} \\
\forall n \in N, \forall t \in T \\
C O P_{C O C} M_{n, t, C O C}+C O P_{A B C} M_{n, t, A B C}+N_{n, t, C S}^{d i s}-N_{n, t, C S}^{c h}=\sum_{u \in U} X_{n, u} D_{u, t}^{c o o l} \quad \forall n \in N, \forall t \in T \\
n_{G B, h e a t}\left(M_{n, t, G B}-M_{n, t, A B C}\right)+n_{C H P, h e a t} M_{n, t, C H P}+n_{B I O} M_{n, t, B I O}+C O P_{G S H P} M_{n, t, G S H P}+N_{n, t, H S}^{d i s}-N_{n, t, H S}^{c h}=\sum_{u \in U} X_{n, u} D_{u, t}^{\text {heat }} \\
\forall n \in N, \forall t \in T
\end{gathered}
$$

In addition, due to that $A B C$ absorbs the waste heat gas from $G B$, the energy output from $A B C$ must be less than that of GB, as shown in Eq. (21). Eq. (22) indicated that a building can only belong to one cluster. Meanwhile, one cluster consists of multiple buildings, which is shown in Eq. (23).

$$
\begin{gathered}
M_{n, t, A B C} \leq M_{n, t, G B} \quad \forall n \in N, \forall t \in T \\
\sum_{n \in N} X_{n, u}=1 \quad \forall u \in U \\
\sum_{u \in U} X_{n, u} \geq 1 \quad \forall n \in N
\end{gathered}
$$

In these equations, $n_{i}$ indicates the efficiency of the facility, [-]; $C O P_{C O C}, C O P_{A B C}, C O P_{G S H P}$ represents the coefficient of performance for the COC, ABC, and GSHP, [-]; $M_{n, t, i}$ is a variable that defines the facility $i$ uses the specific energy sources at time step $t$ in $n$ cluster, $[\mathrm{kWh}] ; N_{n, t, k}^{\text {ch }}$ and $N_{n, t, k}^{d i s}$ are variables that represent the charging and discharging flows of the storage facility $k$ at time step $t$ in $n$ cluster, $[\mathrm{kWh}] ; X_{n, u}$ is a binary variable representing the energy demand of $u$ building is supplied by cluster $n,[-] ; D_{u, t}^{\text {elec }}, D_{u, t}^{\text {cool }}$ and $D_{u, t}^{\text {heat }}$ are deterministic parameters representing the electric, heating and cooling demand of $u$ building at the time step $t$, respectively, [kWh]. 
To guarantee that specific facilities use specific energy sources, the following equation constraints are necessary.

$$
\left\{\begin{array}{l}
M_{n, t, \text { grid }}=C P_{n, t, \text { grid }} \\
M_{n, t, G B}+M_{n, t, C H P}=C P_{n, t, g a s} \\
M_{n, t, b i o}=C P_{n, t, b i o}
\end{array}\right\} \forall n \in N, \forall t \in T
$$

where $C P_{n, t, m}$ defines the consumption of energy carrier $m$ at time step $t$ in $n$ cluster, [kWh].

Here, the energy storage facilities are set to take a day as an operation cycle. The energy stored in battery and heating storage at time step $t+1$ equals to the energy stored at time step $t$, multiplied by the loss fraction, plus the energy net flow of the storage ( $\mathrm{Li}$ et al., 2016).

$$
S_{n, t+1, k}=S_{n, t, k} \times\left(1-n_{k}^{\text {loss }}\right)^{\Delta T}+\left(N_{n, t, k}^{c h}-N_{n, t, k}^{d i s}\right) \times \Delta T \quad \forall n \in N, \forall t \in T \backslash \bar{T}, \forall k \in K
$$

where $S_{n, t, k}$ represents the amount of energy stored by storage facility $k$ during time step $t$ in cluster $n,[\mathrm{kWh}] ; n_{k}^{\text {loss }}$ denotes the loss fraction, [-].

\subsubsection{Technical Constraints}

Eq. (26) indicated that The binary variable $B_{n, i}$ must be equal to 1 as long as the facility $i$ is selected in cluster $n$, and the capacity of facility cannot exceed the maximum value Max, which is set as $10^{4}$.

$$
W_{n, i} \leq B_{n, i} \operatorname{Max} \quad \forall n \in N, \forall i \in I
$$

During the operation process, the energy output from the energy generation facilities cannot exceed the capacity, as shown in Eq. (27). Meanwhile, the energy stored in the energy storage facilities must be less than the capacity, as shown in Eq. (28).

$$
\begin{gathered}
M_{n, t, j} \leq W_{n, j} \quad \forall n \in N, \forall t \in T, \forall j \in J \\
S_{n, t, k} \leq W_{n, k} \quad \forall n \in N, \forall t \in T, \forall k \in K
\end{gathered}
$$

Due to the limited installation area and volume of DES in each district, there is an upper limit for the capacity of energy storage facilities and GSHP. At the same time, for a cluster, the total installed area of PV panels should be less than or equal to the sum of the installable areas of all buildings that belong to the cluster, as shown in Eq. (31).

$$
\begin{gathered}
W_{n, k} \leq S_{k}^{\max } \quad \forall n \in N, \forall k \in K \\
W_{n, G S H P} \leq S_{G S H P}^{\max } \quad \forall n \in N \\
W_{n, P V} \leq \sum_{u \in U} X_{n, u} S_{u}^{\text {roof }} \quad \forall n \in N
\end{gathered}
$$

\subsection{Solution Method}

The model was formulated as the MOMP, and the optimization was performed in MATLAB 2015. The augmented $\varepsilon$-constraint method, weighting method, and Nondominated Sorting Genetic Algorithm II (NSGA-II) are widely accepted to solve the MOMP model. It should be noted that NSGA-II is generally applied to multi-objective nonlinear model (Wang et al., 2018), and the 
augmented $\varepsilon$-constraint method and weighting method are accepted to solve the multi-objective linear model. In this study, the augmented $\varepsilon$-constraint method is adopted to solve the MOMP model (Esmaili et al., 2011; Mavrotas, 2009) due to that it can find the optimal solutions more quickly and effectively than the weighting method, which is formulated as shown in Eq. (32). On the one hand, the lexicographic optimization for the payoff table is introduced to avoid calculating of the range of the objective functions on the efficient set. On the other hand, the objective function constraints are converted into equalities by explicitly incorporating the appropriate slack or surplus variables to produce efficient solutions.

$$
\begin{aligned}
& \min \left(f_{1}(x)+e p s \times\left(s_{2}+s_{3}+\cdots+s_{\mathrm{p}}\right)\right) \\
& \text { st } f_{2}(x)-s_{2}=e_{2}, f_{3}(x)-s_{3}=e_{3}, \cdots, f_{p}(x)-s_{p}=e_{p} \quad x \in S \text { and } s_{i} \in R^{+} .
\end{aligned}
$$

where, $x$ defines the vector of decision variables, including the selection of facilities, capacity of facilities, operating power of facilities, and the division of building clusters; $s_{i}$ represents the slack variables that used to transform the mathematical model of non-standard linear programming problems into standard ones; $f_{1}(x), f_{2}(x), \ldots, f_{p}(x)$ are the $p$ objective function, and $S$ is the feasible region; eps is a smaller number that set as $10^{-3}$.

\section{Case study}

To verify the applicability of the proposed mathematical model, in this part, a district including four building categories (four hotel buildings, four office buildings, one school building, and six residential buildings) located in Xuzhou, China is set as an example. The location of the buildings is visible in Fig. 4, and the information of the buildings is shown in Table 1.

Table 1. Description of different building types.

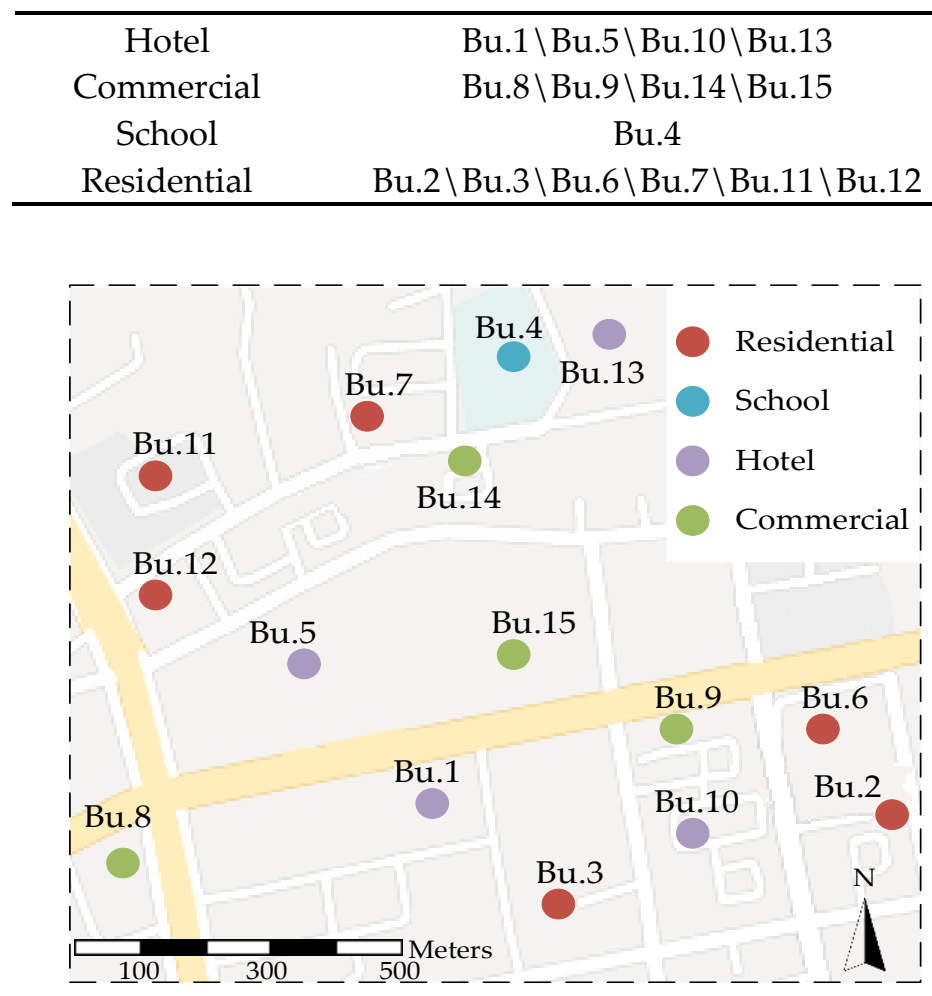


Figure 4. Geographic layout of the studied buildings.

\subsection{Input parameter}

\subsubsection{Energy Demands and Weather information}

Xuzhou is located at the eastern of China with a typical continental monsoon climate. Three typical days are selected to represent the winter (November-December, January- February), summer (June-August) and mid-season (March-May, September-October), with durations of 92, 153 and 120 days respectively. Fig. 5 shows the solar radiation intensity of Xuzhou on three typical days (Duan et al., 2017).

Based on the field investigation, the electrical, heating and cooling demand of the buildings on three typical days are given in Fig. 6. It can be easily founded that the electricity is essential for all buildings in a whole year. As to the same category of building, the peak demand occurs at the same time basically, whereas the occurrence time of peak demands in building categories is different from each other.

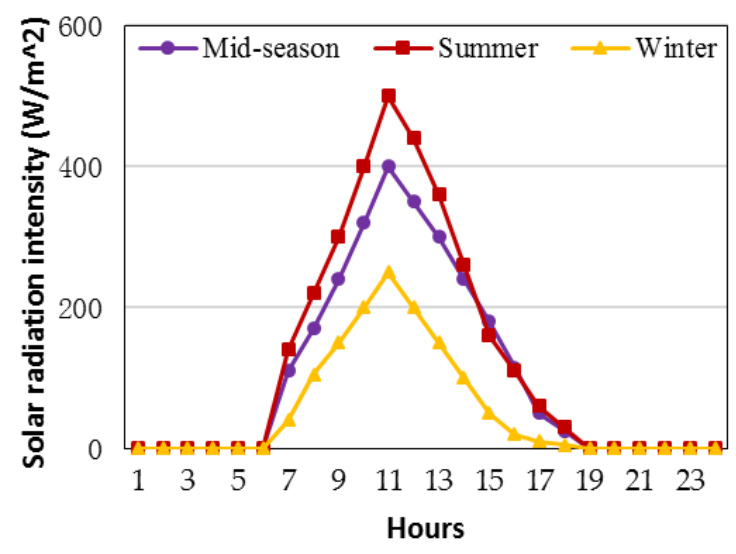

Figure 5. The solar radiation intensity on typical days.
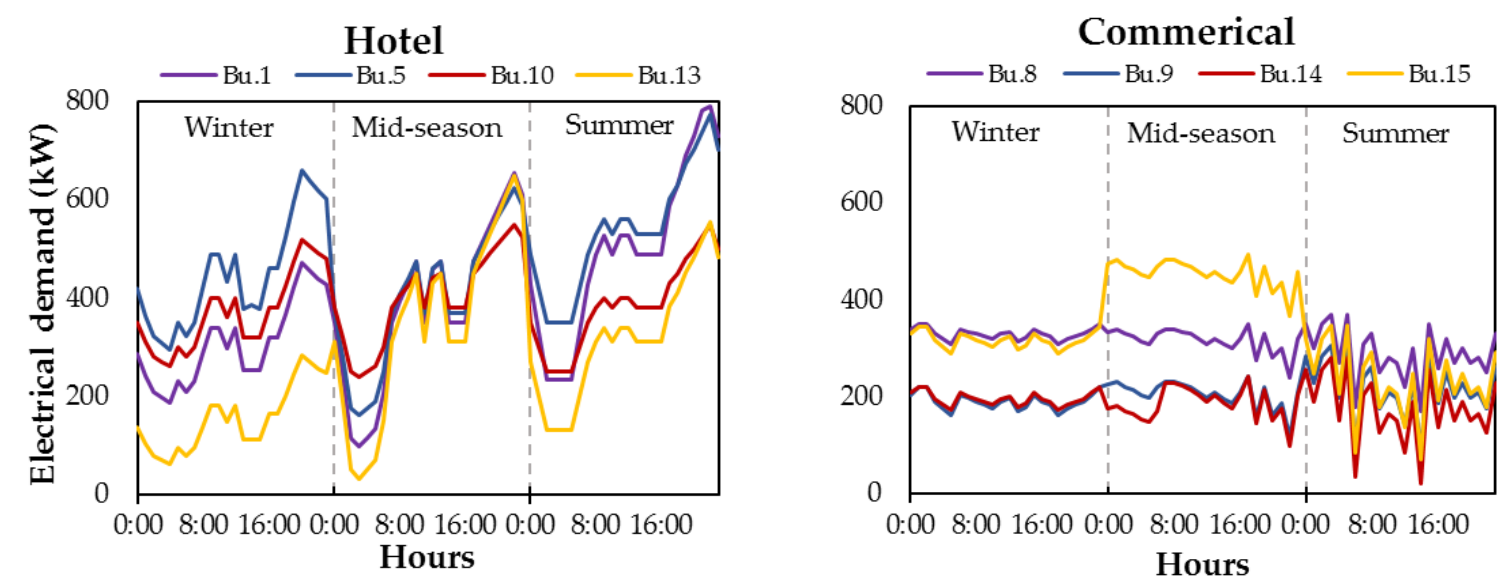

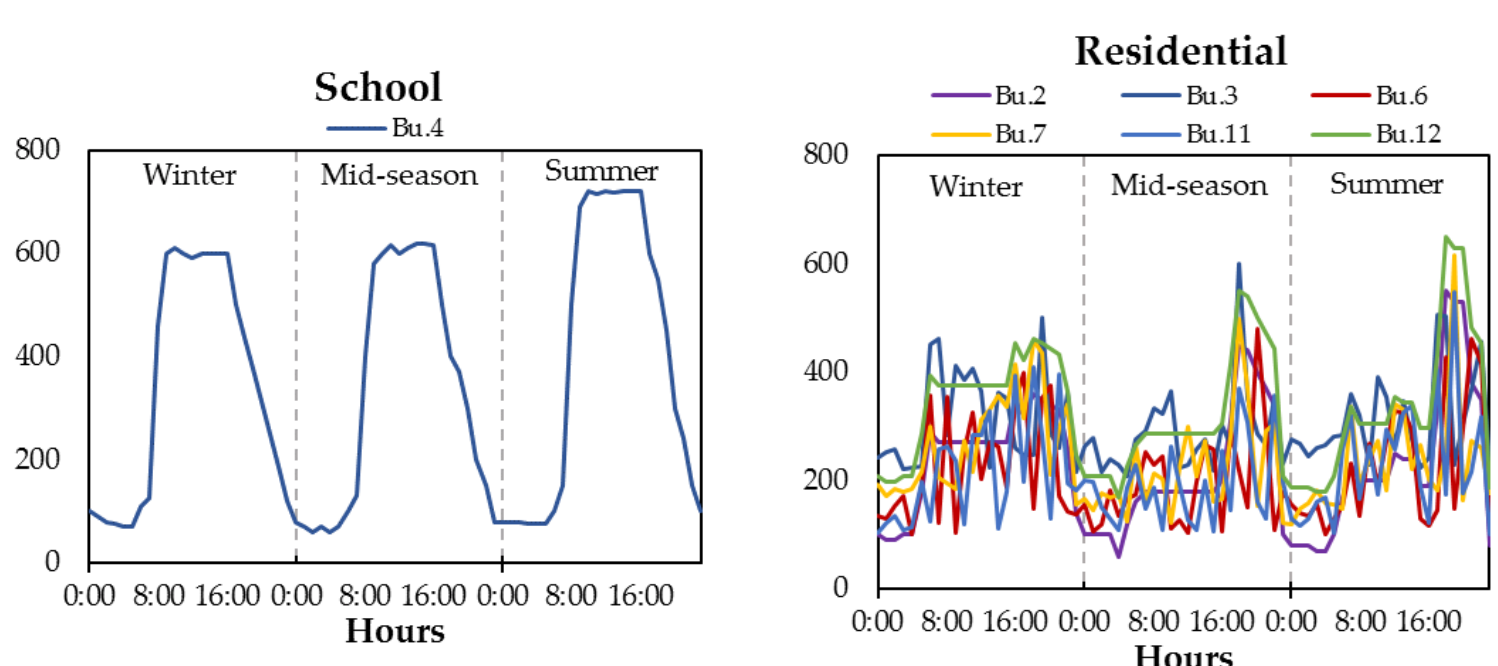

a) Electricity demand

Hotel

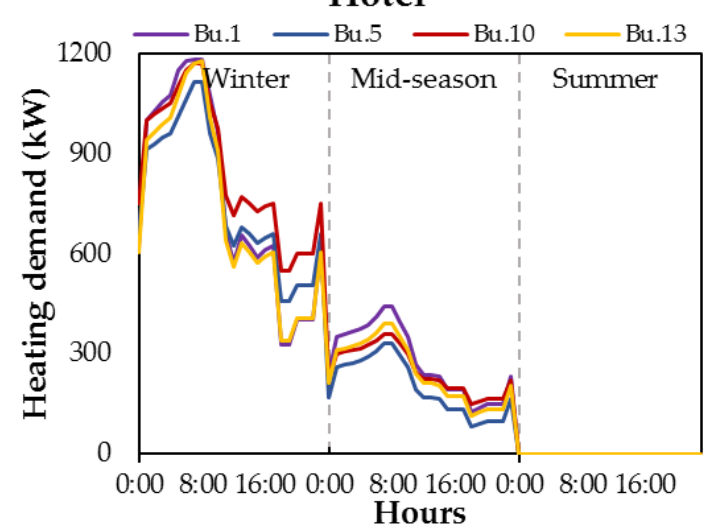

School

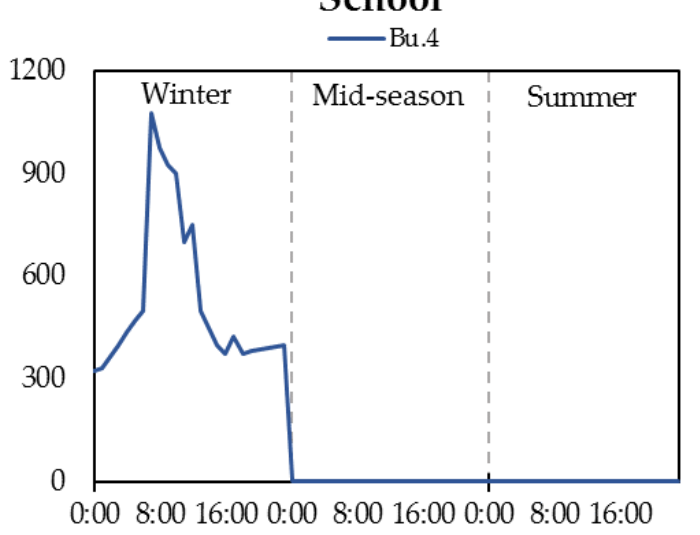

Hours

\section{Commerical}

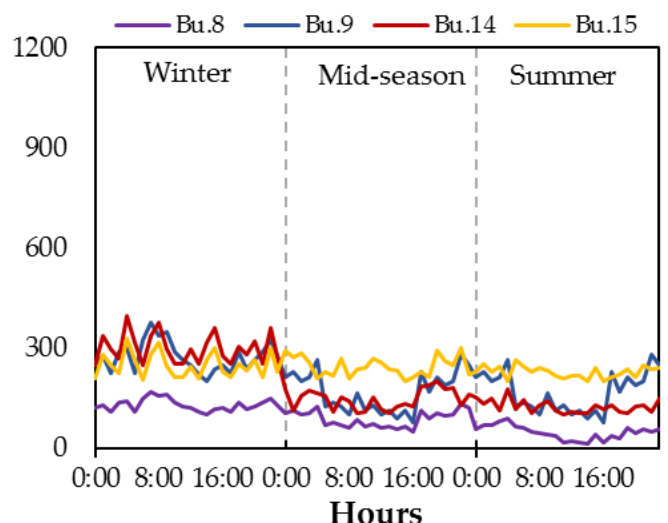

Residential

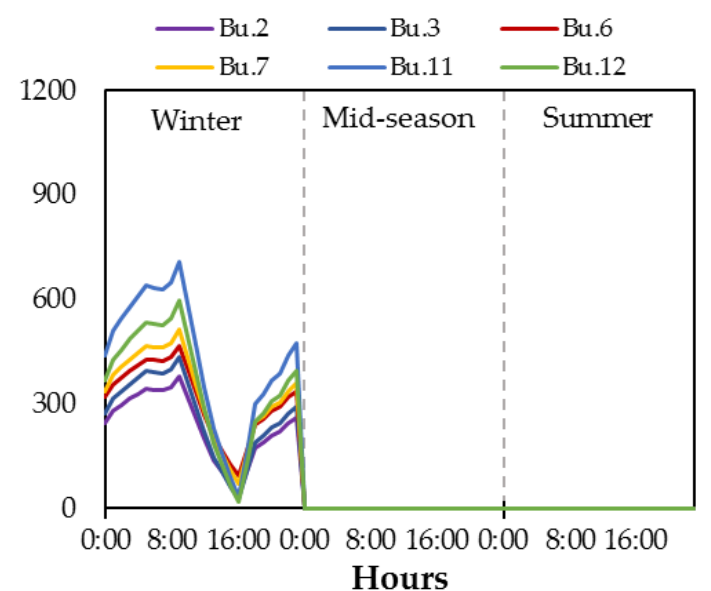

b) Heating demand 

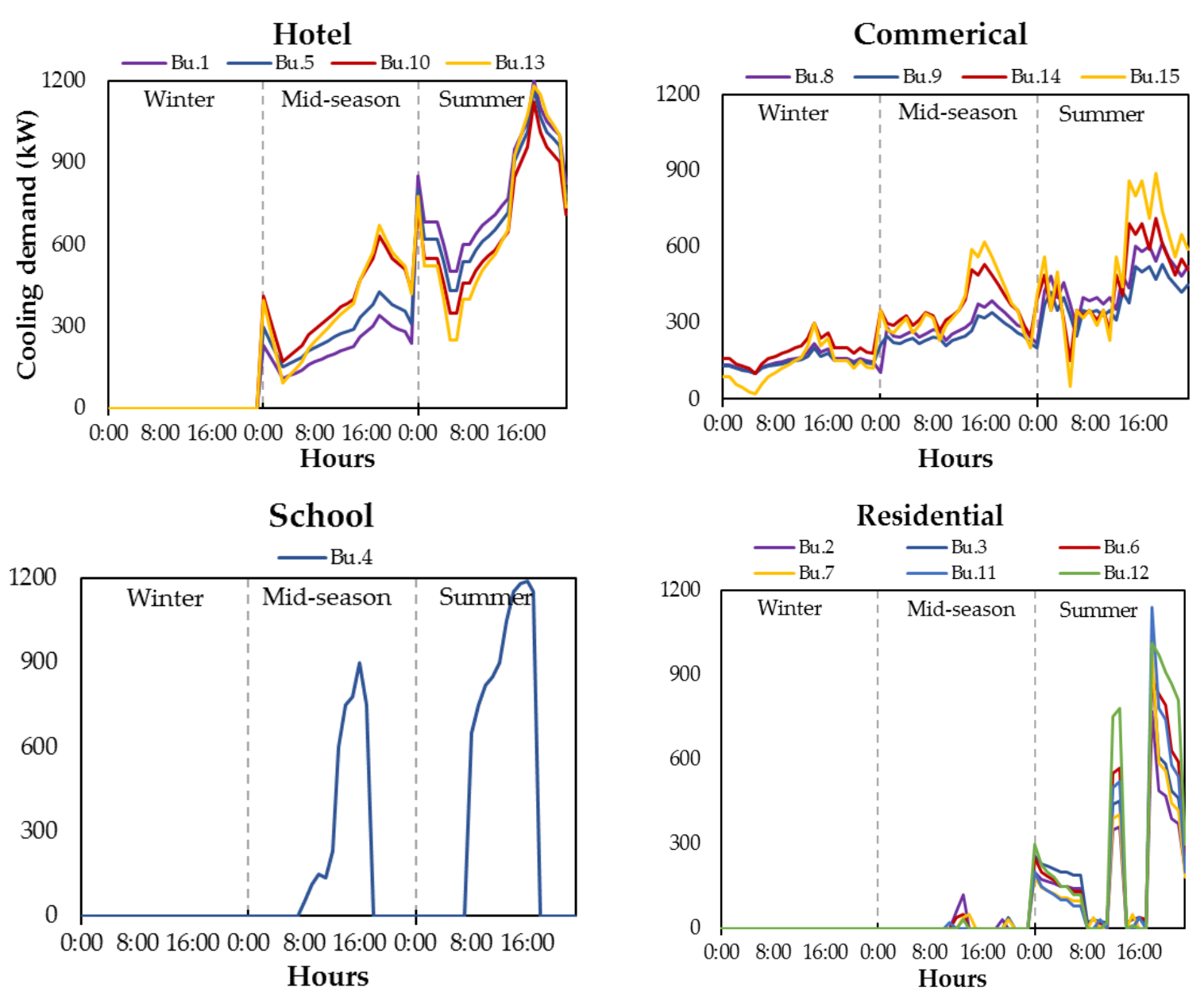

c) Cooling demand

Figure 6. (a) Electricity; (b) Heating; (c) Cooling demand for four building categories at different periods.

\subsubsection{Cost and emission information}

The parameters of DES facility are listed in Table 2 (Arcuri et al., 2007; Di Somma et al., 2017; Li et al., 2016; Ooka and Komamura, 2009; Yang et al., 2015). The size of PV panels is limited by the installation space which is illustrated in Eq. (18). The operation efficiency of the facilities is set to be constant to keep the linear of the proposed model. Furthermore, the electric efficiency of the gas-fired CHP is $35 \%$, and the thermal efficiency is $55 \%$.

Market data, such as energy price and technical information is another important input in the optimization model. Here, according to the result of field investigation, the natural gas price for gas boiler and gas-fired $\mathrm{CHP}$ is constant at $0.055 \mathrm{CHF} / \mathrm{kWh}$ for commercial users. Similarly, the biomass price is $0.014 \mathrm{CHF} / \mathrm{kWh}$. However, there are differences in the price of electricity at different time periods. In detail, the electricity price is $0.15 \mathrm{CHF} / \mathrm{kWh}$ during the peak period (AM 6:00 PM 10:00) and 0.07 CHF/kWh during the off-peak period (PM 11:00 PM 12:00, AM 1:00 AM 5:00). The emission factors of electricity, natural gas, and biomass are set as $9.5 \mathrm{gCO} 2 / \mathrm{kWh}, 198$ $\mathrm{gCO} 2$ / kWh, 0 gCO2 / kWh, respectively (Xing et al., 2019). Moreover, the interest rate is set at $8 \%$ to evaluate the total annual cost of DESs that installed in clusters.

Table 2. Parameters of DES facility. 


\begin{tabular}{ccccc}
\hline Facility & $\begin{array}{c}\text { Maximum } \\
\text { capacity } \\
\left(\mathbf{k W}, \mathbf{k W h} \mathbf{~ m}^{\mathbf{2}}\right)\end{array}$ & $\begin{array}{c}\text { Fixed cost } \\
\mathbf{( C H F )}\end{array}$ & $\begin{array}{c}\text { Linear capacity- } \\
\text { dependent cost } \\
\text { (CHF/kW, CHF/kWh, } \\
\left.\mathbf{C H F} / \mathbf{m}^{2}\right)\end{array}$ & $\begin{array}{c}\text { Rated } \\
\text { efficiency/COP }\end{array}$ \\
\hline $\begin{array}{c}\text { Ground-source } \\
\text { heat pump }\end{array}$ & 2,000 & 94,120 & 1,670 & 3.5 \\
Gas boiler & 2,000 & 66,100 & 200 & $87.5 \%$ \\
Biomass boiler & 2,000 & 146,610 & 440 & $85 \%$ \\
Gas-fired CHP & 2,000 & 299,140 & 790 & $90 \%$ \\
Compression & 2,000 & 49,580 & 150 & 4.70 \\
$\quad$ chiller & 2,000 & 76,015 & 230 & 1.45 \\
Absorption chiller & 300 & 5,750 & 290 & $15 \%$ \\
PV panels & 1,000 & 1685 & 12.5 & $90 \%$ \\
Heating storage & 1,000 & - & 2000 & $90 \%$ \\
Batteries & 1,000 & 1685 & 12.5 & $90 \%$ \\
Cooling storage & 1,000 & \\
\hline
\end{tabular}

\subsubsection{Technical information}

Here, the system lifespan is set as 15 years, and the technical information is listed in Table 3. The carbon emission factors of steel, copper and aluminum materials are $3.34 \mathrm{~kg} / \mathrm{kg}, 7.58 \mathrm{~kg} / \mathrm{kg}$, $12.63 \mathrm{~kg} / \mathrm{kg}$, respectively. The main material of PV panels is monocrystalline silicon, the specific technical information can be found in (de Wild-Scholten, 2013).

Table 3. Technical information of DES facility.

\begin{tabular}{cccccc}
\hline Facility & $\begin{array}{c}\text { Steel } \\
\text { content (\%) }\end{array}$ & $\begin{array}{c}\text { Copper } \\
\text { content (\%) }\end{array}$ & $\begin{array}{c}\text { Aluminum } \\
\text { content (\%) }\end{array}$ & $\begin{array}{c}\text { Consumable } \\
\text { coefficient } \\
\mathbf{( k g} / \mathbf{k g})\end{array}$ & $\begin{array}{c}\text { Production Carbon } \\
\text { Emission Indicator } \\
\mathbf{( k g / k W )}\end{array}$ \\
\hline $\begin{array}{c}\text { Ground-source } \\
\text { heat pump }\end{array}$ & 73.2 & 26.4 & 0.4 & 4.68 & 23.1 \\
$\quad \begin{array}{l}\text { Gas boiler } \\
\text { Biomass boiler }\end{array}$ & 73.7 & 25.5 & 0.8 & 5.22 & 24.7 \\
Gas-fired CHP & 72.2 & 27.0 & 0.8 & 4.95 & 23.7 \\
$\begin{array}{c}\text { Compression } \\
\text { chiller }\end{array}$ & 83.0 & 12.0 & 5.0 & 11.41 & 51.5 \\
$\begin{array}{c}\text { Absorption } \\
\text { chiller }\end{array}$ & 79.4 & 13.3 & 5.0 & 11.52 & 53.1 \\
$\begin{array}{c}\text { Heating storage } \\
\text { Cooling storage }\end{array}$ & 80.7 & 15.2 & 5.4 & 10.67 & 50.4 \\
\hline
\end{tabular}

\subsection{Pareto frontier}

Fig.7 shows the Pareto frontier. It can be found that the range of DES life cycle cost is between $83,825,530 \mathrm{CHF}$ and $111,598,900 \mathrm{CHF}$, and the range of DES life cycle carbon emission is between $40,880 \mathrm{t}$ and $17,358 \mathrm{t}$. The point $a$ is obtained only when considering environmental objective, and the point $b$ is obtained only when considering economic objective. Each point on the Pareto frontier represents a different optimal cluster solution and energy allocation scheme as well as the configuration of DESs, so as to provide different choices for designers. 


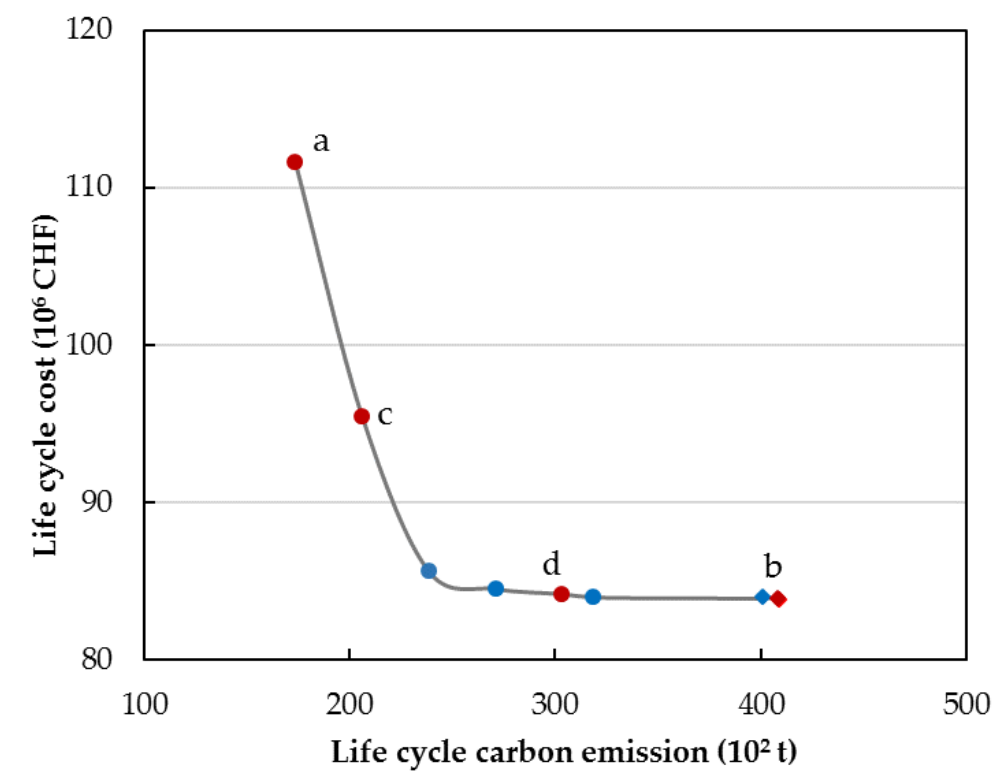

Figure 7. Pareto frontier obtained under the environmental and economic objectives.

\subsection{Results and Discussions}

\subsubsection{Optimized clusters and DES configurations}

Before optimization, the first building cluster includes four buildings (Bu.4, Bu.7, Bu.13, Bu.14), the second building cluster includes six buildings (Bu.1, Bu.5, Bu.8, Bu.11, Bu.12, Bu.15), and the third building cluster consists of five buildings (Bu.2, Bu.3, Bu.6, Bu.9, Bu.10). The conventional energy system is implemented in three building clusters, in which the electricity is purchased from the grid, and the heating and cooling demand are met by gas boilers and compression chillers, respectively. The life cycle carbon footprint distribution of the conventional energy system is shown in Fig. 8. The life cycle carbon emissions are equal to $59122 \mathrm{t}$.

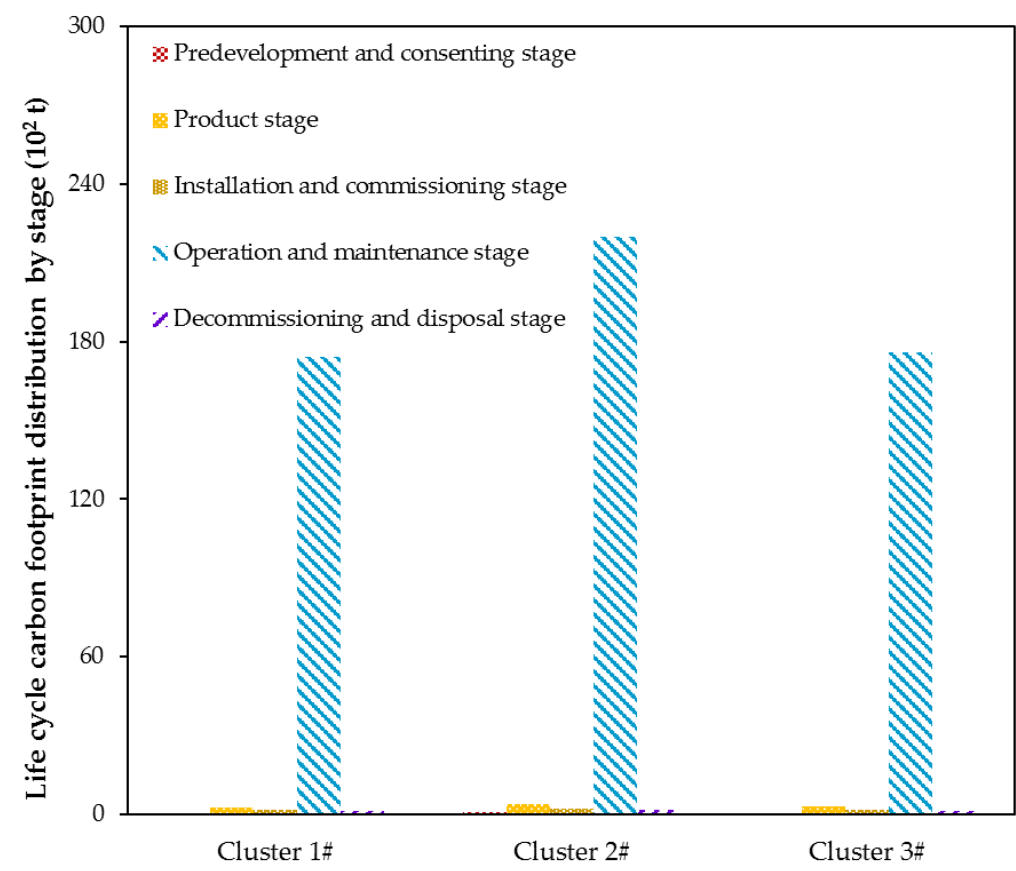

Figure 8. Life cycle carbon footprint distribution by stage in the conventional energy system. 
The optimized building clusters for four points are shown in Table 4. It can be noted that the same DES don't supply energy to the same building category, on the contrary, the energy demand characteristics of different categories of buildings are combined to achieve the economic and environmental goals. For different objective functions, there are also great differences in cluster schemes. Moreover, the optimized energy allocation schemes and selection of facilities for four points are shown in Table 5. It can be noted that the capacities of all facilities reach the maximum only when considering environmental objective to reduce the energy consumption as much as possible. The total capacity of ground-source heat pumps decreases as the proportion of economic objective increases and reaches the minimum only when considering economic objective. This emphasizes the importance of ground-source heat pump for the environmental objective, due to the high coefficient of performance, thereby consuming less electricity with a low carbon emission coefficient to satisfy the heating demand of buildings.

Biomass boilers' total capacity reaches the maximum in all configurations, and similarly for PV panels. This emphasizes the superiority of them, due to the possibility of appropriate cost and the utilization of renewable energy, thereby creating excellent economic and environmental benefits. There is a complex relationship between the gas-fired CHPs and gas boilers. The total capacity of gas-fired CHPs is the maximum under environmental objective, whereas they are not selected under a lower economic objective (at point $\mathrm{d}$ ). However, the total capacity of gas boilers is the maximum under a lower economic objective (at point $\mathrm{d}$ ). Moreover, along with the change of the objective function, the variation tendency of the total capacities of gas-fired CHPs and gas boilers become complicated, which can attribute to that the economic and environmental objectives are related to many factors including the operation efficiency of facility, carbon emission coefficient of energy and energy price. But it's no doubt that the capacity selection results are obtained by pursuing the optimal value of the objective function on the premise of meeting the heating demand of buildings.

As the main cooling energy supply facilities, the compression chillers consume electricity, and the absorption chillers consume the waste gas from the gas boiler to meet the cooling demand of buildings. Although the compression chillers have the high investment cost and conversion efficiency, the total capacity of absorption chillers is larger than compression chillers only when considering economic objective and a lower proportion of economic objective (at point $\mathrm{d}$ ). This is because that the price of electricity input to the compression chillers is higher than the price of natural gas input to the absorption chillers, resulting in more natural gas being required to satisfy the cooling demand of buildings, which also explains the larger capacity of absorption chillers is required.

The capacity of cooling storages reaches the maximum in all configurations, highlighting the role in peak shaving, especially thanks to the high efficiency and the low investment cost. Unlike cooling storage facilities, the total capacity of batteries for electricity demand has a strong relationship with the sizing of compression chillers and ground-source heat pumps, the total capacity of heating storages is related to the sizing of all heating generation facilities including ground-source heat pumps, gas boilers, biomass boilers, and gas-fired CHP. But overall, the total capacities of heating storages and batteries increase as the proportion of the environmental objective increases. This result illustrates the superiority of storage facilities for the environmental purpose because of the possibility of reducing unnecessary loss of energy. 
Table 4. Optimized clusters at four points.

\begin{tabular}{|c|c|c|c|c|c|}
\hline $\begin{array}{l}\text { Optimized } \\
\text { Solution }\end{array}$ & $\begin{array}{c}\text { Energy supply } \\
\text { buildings }\end{array}$ & Point a & Point c & Point d & Point $b$ \\
\hline \multirow{4}{*}{ Cluster 1} & Hotel & Bu.1 & Bu.1\Bu.5 & Bu.1 & Bu.1\Bu.5 \\
\hline & Commercial & Bu.14 & Bu.15 & Bu.9\Bu.15 & Bu.15 \\
\hline & School & Bu.4 & - & - & - \\
\hline & Residential & Bu.2\Bu.6 & Bu.6 & Bu.2\Bu.3 & Bu.6 \\
\hline \multirow{4}{*}{ Cluster 2} & Hotel & Bu. 5 & Bu.13 & Bu. 5 & Bu.10 \\
\hline & Commercial & Bu.9\ Bu.15 & Bu.14 & Bu. $8 \backslash \mathrm{Bu} .14$ & $\mathrm{Bu} .8 \backslash \mathrm{Bu} .9$ \\
\hline & School & - & Bu.4 & - & - \\
\hline & Residential & Bu.11\Bu.12 & Bu.2\Bu.12 & Bu.7\Bu.12 & $\begin{array}{c}\text { Bu. } 3 \backslash \mathrm{Bu} .7 \backslash \\
\text { Bu.11 }\end{array}$ \\
\hline \multirow{4}{*}{ Cluster 3} & Hotel & Bu.10 \Bu.13 & Bu.10 & Bu.10 \Bu.13 & Bu.13 \\
\hline & Commercial & Bu. 8 & $\mathrm{Bu} .8 \backslash \mathrm{Bu} .9$ & - & Bu.14 \\
\hline & School & - & - & Bu.4 & Bu.4 \\
\hline & Residential & Bu.3\Bu.7 & \begin{tabular}{c} 
Bu.3\Bu.7\} $\\
{\text { Bu.11 }}$ & Bu.6\Bu.11 & Bu. $2 \backslash \mathrm{Bu} .12$ \\
\hline
\end{tabular}
\end{tabular}

Table 5. Optimized DES configurations for each cluster at four points.

\begin{tabular}{|c|c|c|c|c|c|}
\hline $\begin{array}{l}\text { Optimized } \\
\text { Solution }\end{array}$ & Clusters & Point a & Point c & Point d & Point $b$ \\
\hline \multirow{4}{*}{$\begin{array}{l}\text { Ground-source } \\
\text { heat pump } \\
(\mathrm{kW})\end{array}$} & Cluster 1 & 2000 & 383 & - & - \\
\hline & Cluster 2 & 2000 & 500 & - & - \\
\hline & Cluster 3 & 2000 & 434 & 309 & - \\
\hline & Total capacity & 6000 & 1317 & 309 & - \\
\hline \multirow{4}{*}{$\begin{array}{l}\text { Gas boiler } \\
\text { (kW) }\end{array}$} & Cluster 1 & 2000 & - & 2000 & 1909 \\
\hline & Cluster 2 & 2000 & 736 & 2000 & - \\
\hline & Cluster 3 & 2000 & 233 & 2000 & 2000 \\
\hline & Total capacity & 6000 & 969 & 6000 & 3909 \\
\hline \multirow{4}{*}{$\begin{array}{c}\text { Biomass boiler } \\
(\mathrm{kW})\end{array}$} & Cluster 1 & 2000 & 2000 & 2000 & 2000 \\
\hline & Cluster 2 & 2000 & 2000 & 2000 & 2000 \\
\hline & Cluster 3 & 2000 & 2000 & 2000 & 2000 \\
\hline & Total capacity & 6000 & 6000 & 6000 & 6000 \\
\hline \multirow{4}{*}{$\begin{array}{c}\text { Gas-fired CHP } \\
(\mathrm{kW})\end{array}$} & Cluster 1 & 2000 & 2000 & - & - \\
\hline & Cluster 2 & 2000 & 2000 & - & 2000 \\
\hline & Cluster 3 & 2000 & 2000 & - & - \\
\hline & Total capacity & 6000 & 6000 & - & 2000 \\
\hline \multirow{4}{*}{$\begin{array}{l}\text { Compression } \\
\text { chiller } \\
(\mathrm{kW})\end{array}$} & Cluster 1 & 2000 & 795 & 517 & 380 \\
\hline & Cluster 2 & 2000 & 781 & 513 & 886 \\
\hline & Cluster 3 & 2000 & 1040 & 403 & 513 \\
\hline & Total capacity & 6000 & 2316 & 1433 & 1779 \\
\hline \multirow{4}{*}{$\begin{array}{l}\text { Absorption } \\
\text { chiller } \\
(\mathrm{kW})\end{array}$} & Cluster 1 & 2000 & - & 2000 & 1909 \\
\hline & Cluster 2 & 2000 & 736 & 2000 & - \\
\hline & Cluster 3 & 2000 & 233 & 2000 & 2000 \\
\hline & Total capacity & 6000 & 969 & 6000 & 3909 \\
\hline \multirow{5}{*}{$\begin{array}{l}\text { PV panels } \\
\left(\mathrm{m}^{2}\right)\end{array}$} & Cluster 1 & 1200 & 1200 & 1500 & 1500 \\
\hline & Cluster 2 & 1800 & 1500 & 1500 & 1500 \\
\hline & Cluster 3 & 1500 & 1800 & 1500 & 1500 \\
\hline & Total capacity & 4500 & 4500 & 4500 & 4500 \\
\hline & Cluster 1 & 1000 & 1000 & 1000 & 1000 \\
\hline
\end{tabular}




\begin{tabular}{cccccc}
\hline Heating & Cluster 2 & 1000 & 1000 & 1000 & 1000 \\
storage & Cluster 3 & 1000 & 1000 & 1000 & 651 \\
$(\mathrm{kWh})$ & Total capacity & 3000 & 3000 & 3000 & 2651 \\
& Cluster 1 & 1000 & 1000 & 175 & 292 \\
Battery & Cluster 2 & 1000 & 1000 & 687 & 468 \\
$(\mathrm{kWh})$ & Cluster 3 & 1000 & 1000 & 384 & 358 \\
& Total capacity & 3000 & 3000 & 1246 & 1118 \\
Cooling & Cluster 1 & 1000 & 1000 & 1000 & 1000 \\
storage & Cluster 2 & 1000 & 1000 & 1000 & 1000 \\
$(\mathrm{kWh})$ & Cluster 3 & 1000 & 1000 & 1000 & 1000 \\
Total annual cost (106 CHF) & 111.60 & 85.57 & 83.95 & 3000 \\
Total carbon emission $\left(10^{2} \mathrm{t}\right)$ & 17,358 & 20,608 & 30,358 & 40,880 \\
\hline
\end{tabular}

\subsubsection{Correlation between DES carbon footprint by facility attributes under two objectives}

The DES life cycle carbon footprint by facility attributes obtained under the economic and environmental optimization are presented in Fig.9.

Fig.9 (a) presents the life cycle carbon footprint from electricity of each DES generated by power grid, PV panels and CHPs for three clusters. Under both economic and environmental optimization, the life cycle carbon emission from electricity generated by the power grid far exceeds the CHPs and solar panels, highlighting the power grid is convenient for both objectives. Moreover, only when considering the economic objective, the carbon emission from electricity generated by CHPs in cluster 2\# is larger than other clusters, and it is also larger than the carbon emission from electricity generated by CHPs only when considering environmental objective, which partly due to the higher heating demand of buildings in cluster $2 \#$ under economic optimization but even more so due to the more contribution of the power grid for meeting the electricity demand under environmental optimization. It can also be found that the carbon emission from electricity generated by PV panels under two objectives is equal to 0 as it inputs solar energy. As for the battery, the total flow rate under environmental optimization is larger than only when considering economic objective, which illustrates the larger carbon emission flow rate only when considering the environmental objective.

Fig.9 (b) shows the life cycle carbon footprint from heating of each cluster generated by gas boilers, CHPs, and biomass boilers as well as ground-source heat pumps under economic and environmental optimization. It can be easily found that the carbon emission generated by biomass boilers under both economic and environmental optimization is equal to 0 despite the capacity of biomass boilers reaches the maximum under two objectives. This emphasizes the importance of biomass boilers under both objectives, due to the low investment cost and energy carbon emission factor. Ground-source heat pumps are only selected only when considering the environmental objective, but not selected under economic objective. For heating storage, it's more used under the environmental objective than under the economic one, which also illustrates that larger carbon emission flow rate only when considering the environmental objective.

Fig.9 (c) presents the life cycle carbon footprint from cooling of each cluster generated by compression chillers and absorption chillers. It can be known that the capacity of compression chillers is the maximum under both environmental and economic optimization, emphasizing the superiority of compression chillers under two objectives. At the same time, the carbon emission generated by compression chillers is the maximum under economic objective. Moreover, just as 
presented in the previous subsection, absorption chillers are not selected in cluster 2\# under environmental optimization, since they are selected in cluster $1 \#$ and cluster $3 \#$ under economic optimization. Therefore, the carbon emission generated by absorption chillers is the maximum only when considering the economic objective because of the high natural gas emission factor. As for cooling storage, there is little difference in carbon emissions flow rate under economic and environmental optimization.

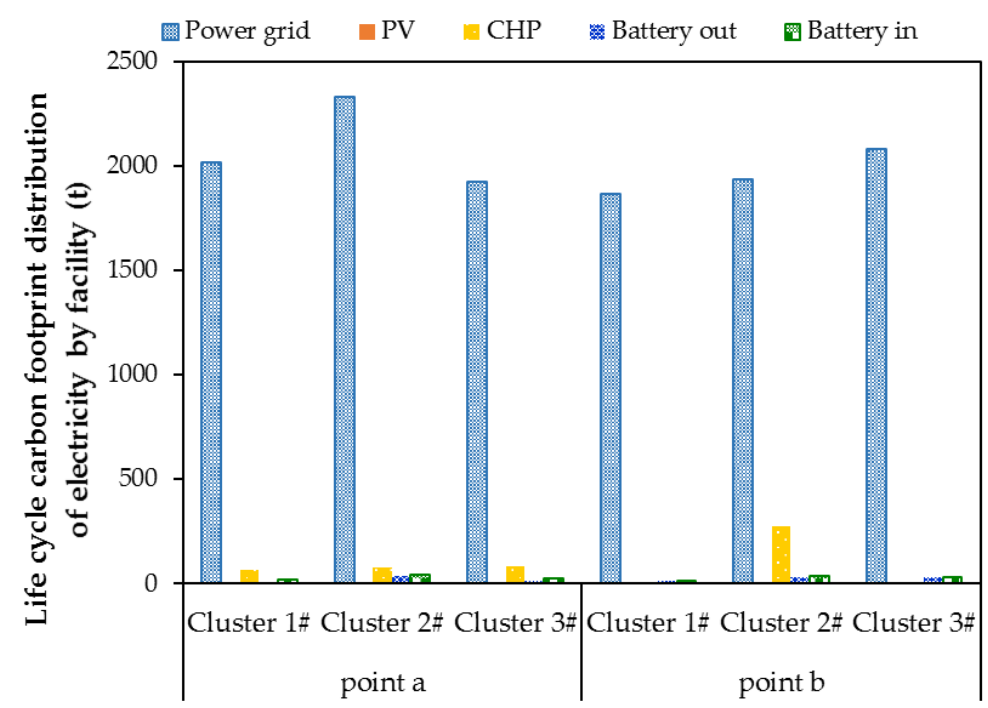

a)

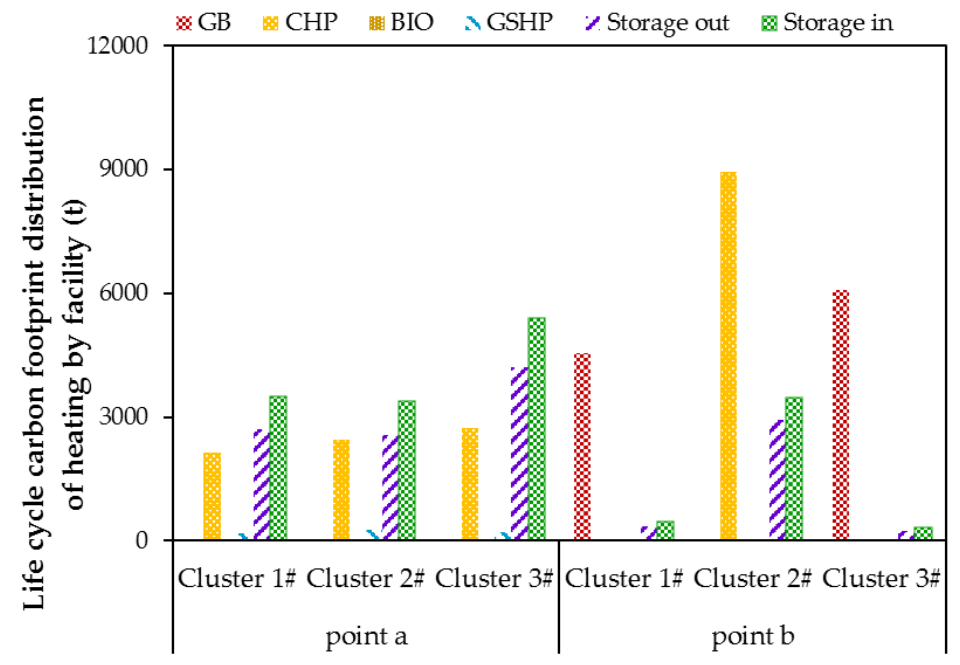

b) 


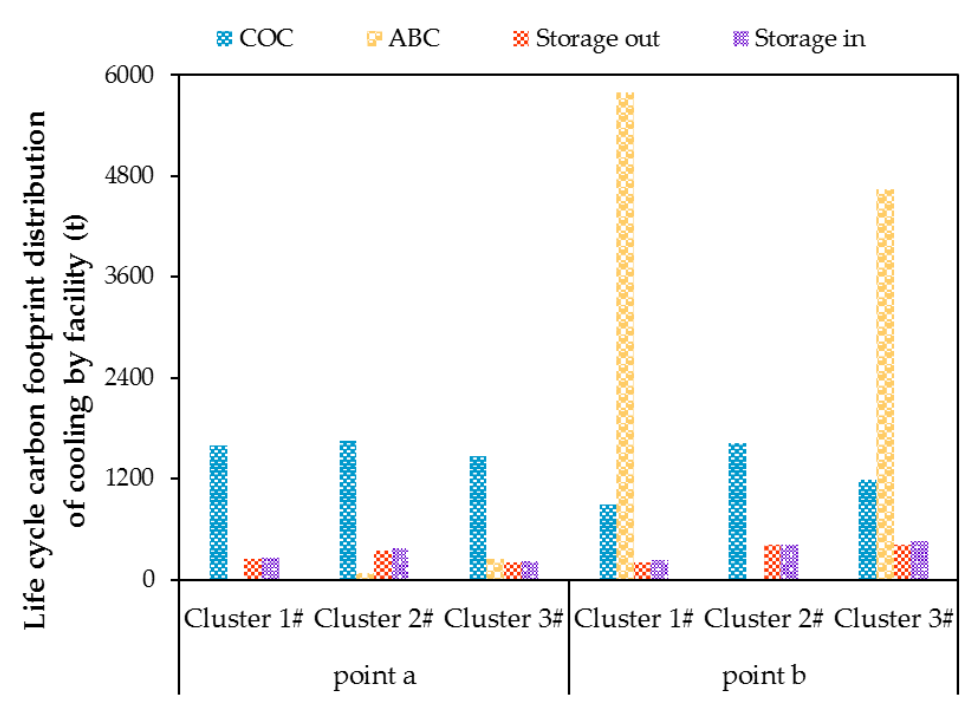

c)

Figure 9. Life cycle carbon footprint distribution of (a) electricity; (b) heating; and (c) cooling by facility at points $a$ and $b$.

\subsubsection{Distribution of DES carbon footprint by stage and source under two objectives}

The Distribution of DES carbon footprint by stage under economic and environmental optimization is presented in Fig.10. Under both economic and environmental objectives, the carbon emissions in operation and maintenance stage account for $88 \% \sim 94 \%$ of building energy system in the whole life cycle, which is due to high energy consumption. Moreover, the difference in carbon emissions under two objectives is mainly caused by the difference in natural gas consumption during the operation and maintenance stage. Meanwhile, the carbon emissions in product stage also represent a big share of the carbon footprint of building energy system, which is attributed to the raw material production, manufacturing and processing. On the contrary, the carbon emissions in the predevelopment and consenting, decommissioning and disposal stages of the system accounts for less than $1 \%$ of the whole life cycle, which can be neglected basically. The results indicate that these two stages (product stage, operation and maintenance stage) have great potential for energy saving and emission reduction. To be specific, the carbon emissions in the operation and maintenance stage can be reduced by improving the system efficiency and using clean energy, such as solar and wind energy. In the product stage, the carbon emissions can be reduced by increasing the proportion of raw materials with low carbon emission factor, such as steel and copper.

The Distribution of DES carbon footprint by source under economic and environmental optimization is presented in Fig.11. It can be seen that natural gas accounts for the highest proportion of total carbon emissions under both economic and environmental objectives, followed by electricity. Other carbon emissions sources, such as transportation by researchers and the transportation of raw materials and waste facility, have a small share of total carbon emissions. Moreover, the carbon emissions from natural gas account for $65-73 \%$ of the life cycle only when considering the environmental objective, while they account for $85-88 \%$ only when considering the economic objective. Carbon emissions from electricity account for $26-34 \%$ and $10-14 \%$ of the life cycle under environmental and economic optimization, respectively. 


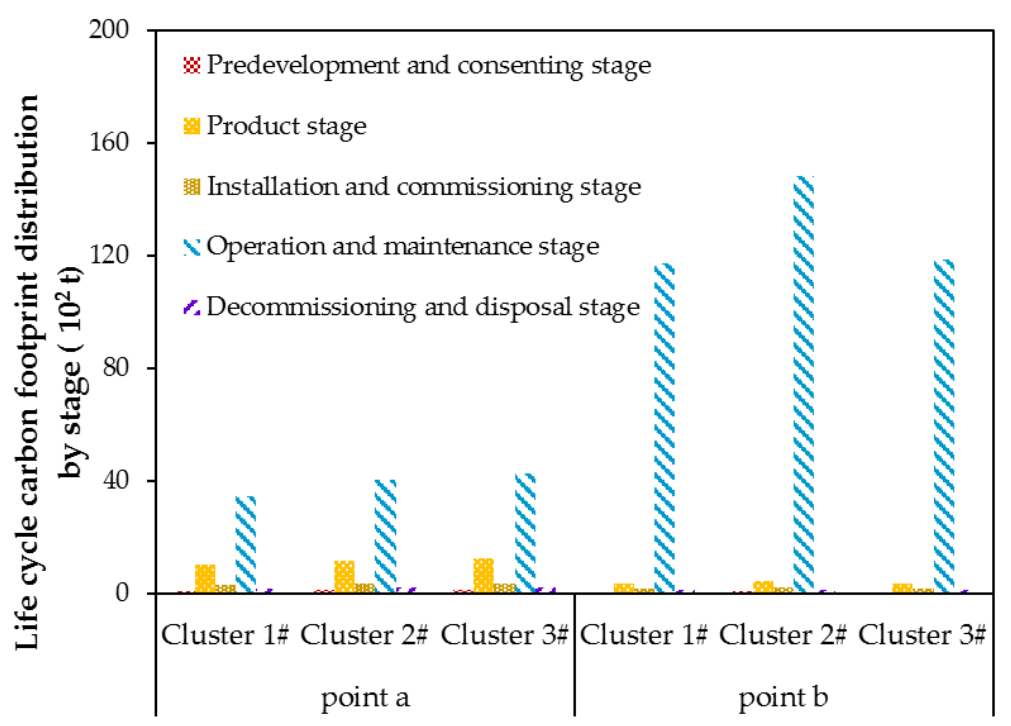

Figure 10. DES life cycle carbon footprint distribution by stage at points $a$ and $b$. 


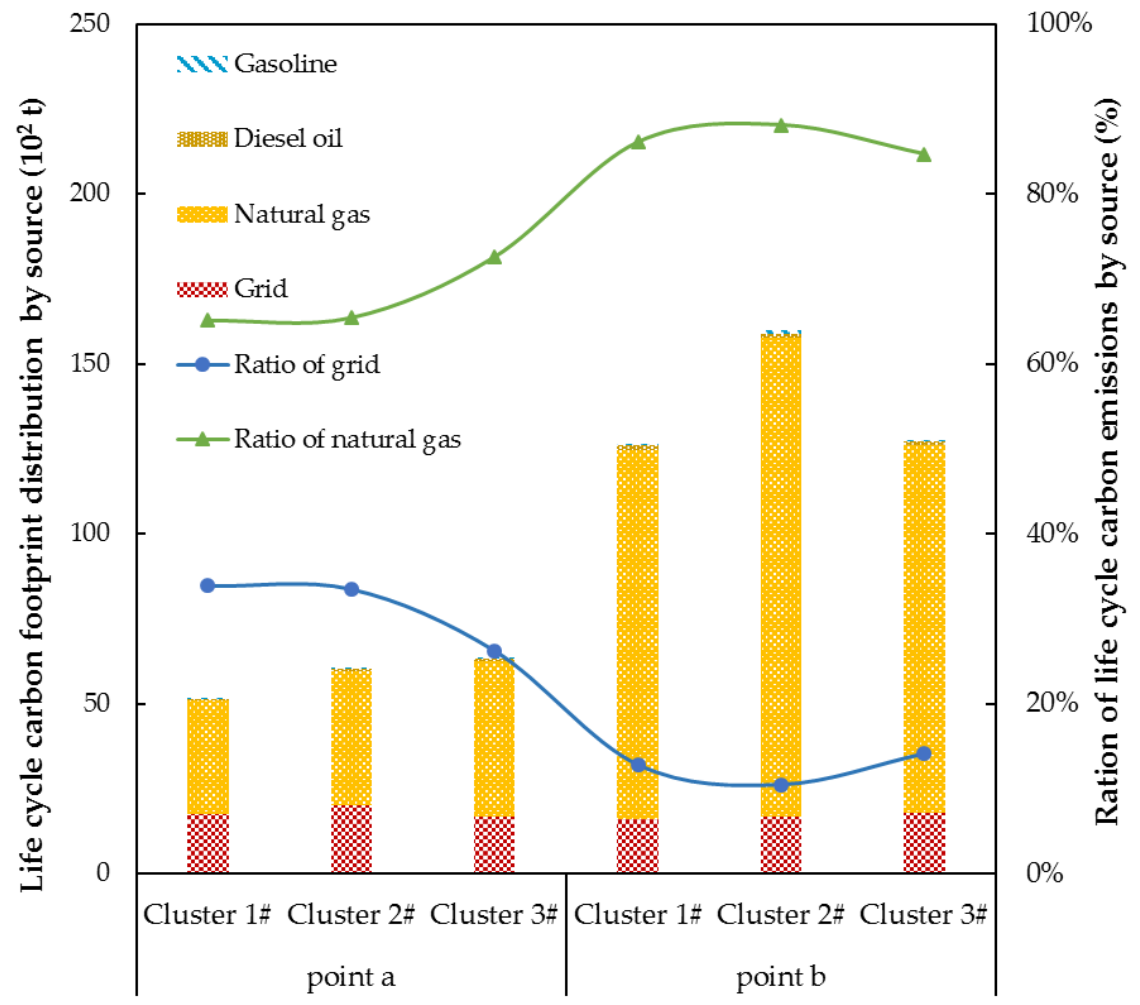

Figure 11. DES life cycle carbon footprint distribution by source at points a and $b$.

\subsubsection{Sensitivity analysis}

Carbon emission factor, an important input of the mathematical model, affects the life cycle carbon emissions of building DES. In the multi-objective model, there is a great effect under a certain proportion of environmental objectives (at points a, c, and d), whereas no effects exist under economic objective (at point $b$ ). Therefore, the effect of carbon emission factor on life cycle carbon emissions of DES under a certain proportion of environmental objectives is investigated in the following. At present, thermal power generation is strictly restricted in China, and new sustainable energy is vigorously developed. It is expected that the carbon emission factors of natural gas and electricity will be reduced to $50 \%$ by 2030 (Tan et al., 2018). Therefore, the environmental performance of the electricity and natural gas carbon emission factors from $10 \%$ to $50 \%$ is explored and discussed in this section.

Fig.12 for electricity carbon emission factor, illustrates the environmental performance as the carbon emission factor of electricity decreases from $10 \%$ to $50 \%$, and the decrease ratio in life cycle emissions is shown Fig.12. Generally, it can be found that the decrease in electricity carbon emission factor has little effect on environmental performance, and the environmental performance is more easily affected only when considering the environmental objective (at point a) compared with other points. In detail, when the electricity carbon emission factor is half of the current one, the life cycle carbon emissions decrease by $9 \%$ to $16 \%$. This emphasizes the important role of electricity carbon emission factor in the life cycle carbon emissions of district energy supply system.

Fig.13 for natural gas carbon emission factor, illustrates the environmental performance as the natural gas carbon emission factor decreases from $10 \%$ to $50 \%$. Fig. 13 shows the decrease of the life 
cycle carbon emissions compared with current gas carbon emission factor, from which it can be found that the gas carbon emission factor has a siginificant effect on the environmental performance compared with electricity. In detail, when the natural gas carbon emission factor is half of the current one, the life cycle carbon emissions decrease by $34 \%$ to $39 \%$. What's more, as the carbon emission factor of natural gas decreases, the consumption of natural gas decreases, while the consumption of electricity and biomass energy increases, resulting in the reduction in life cycle carbon emissions.

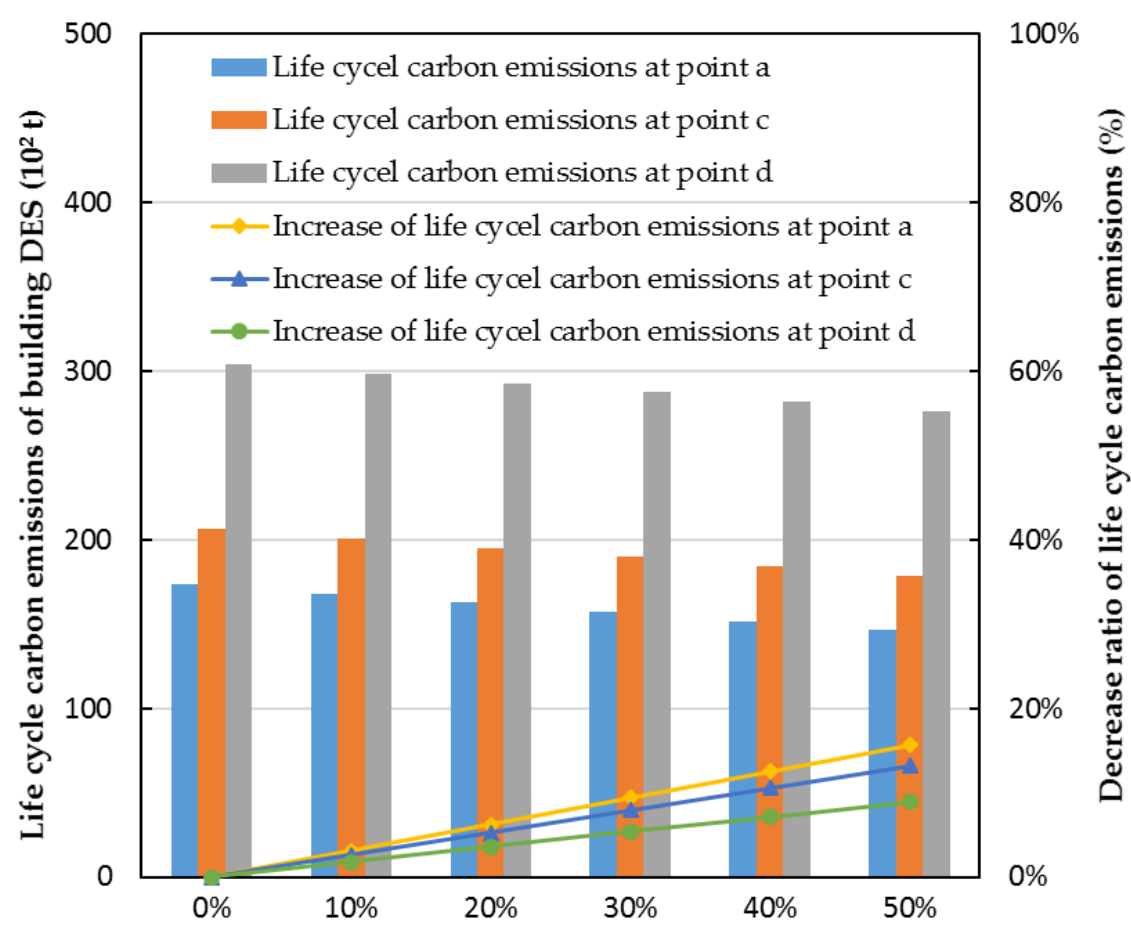

Figure 12. Environmental performance of building DES obtained at points $\mathrm{a}, \mathrm{c}$, and $\mathrm{d}$ for various carbon emission factor of electricity. 


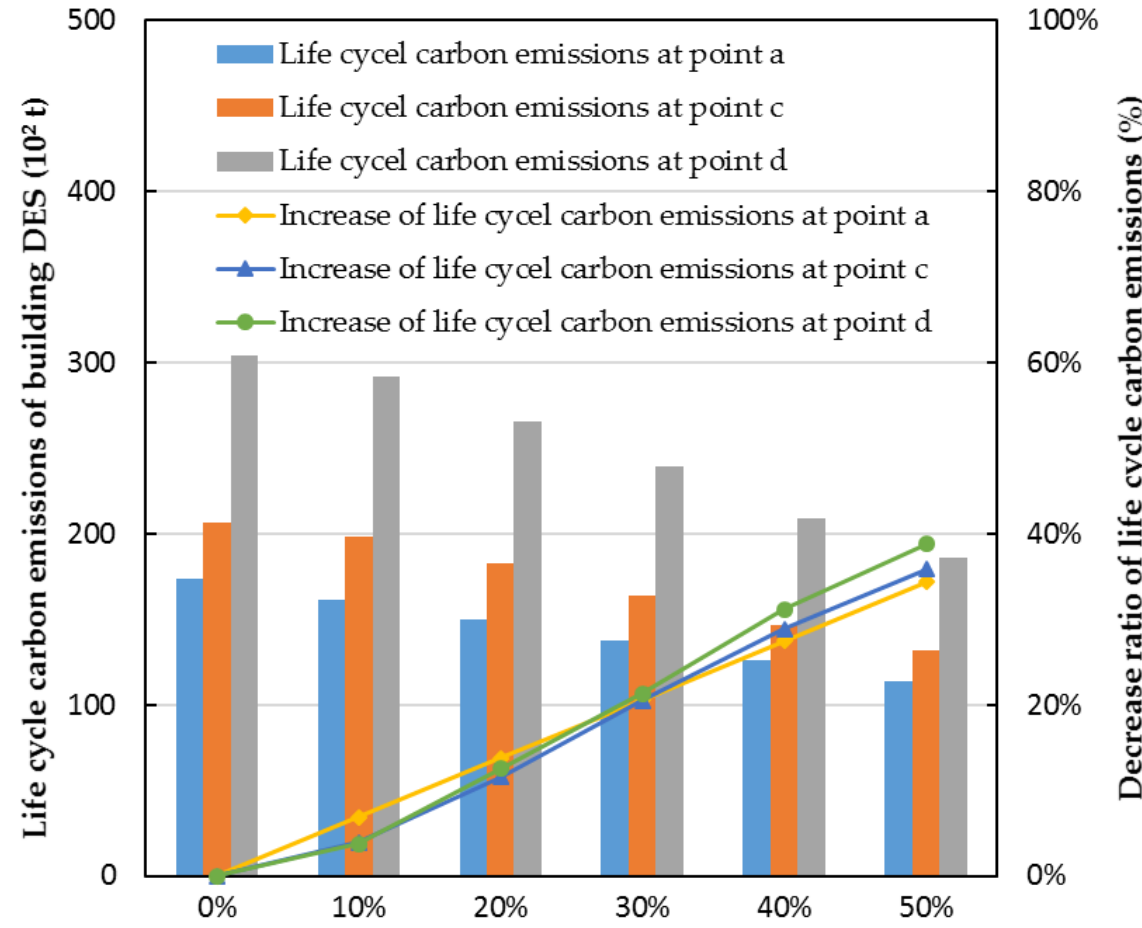

Figure 13. Environmental performance of building DES obtained at points a, c, and d for various carbon emission factor of natural gas.

\section{Conclusions}

This paper develops a quantitative life cycle cost and carbon emissions accounting framework for DES. Based on the LCA theory, a multi-objective model is established while minimizing the life cycle cost and carbon emissions of DES for building clusters. By solving the MOMP model, the Pareto frontier can be obtained and provide designers with good balancing solutions for the environmental and economic performance. The model is applied to the district including fifteen buildings located in Xuzhou, China. Through the case study, it can be found that this model is able to identify the optimal clusters and distributed energy system configurations with minimal life cycle cost and carbon emissions, and several conclusions and recommendations can be drawn as follows:

(1) The developed framework can be used for the quantitative assessment of the life cycle cost and carbon emissions of building distributed energy system, as well as providing designers with guidance on economic and environmental analysis of building distributed energy system.

(2) The proposed multi-objective model is able to obtain the optimal clusters, design and operation schemes of DES for each building cluster in the district, considering the life cycle cost and carbon emissions objectives. Meanwhile, designers can use this method to identify the contribution of facilities, energy sources, and various stages to the carbon footprint distribution of distributed energy system, thus providing key policy guidance on energy saving and emission reduction measures. The method proposed in this study can be applied in any district.

(3) The carbon emission factor of electricity and natural gas can affect the environmental performance of building distributed energy system, and the impact of natural gas emission factors is greater than that of electricity. Specifically, when the electricity carbon emission factor is half of the current one, while life cycle carbon emissions are reduced by $9 \%$ to $16 \%$, and the life cycle 
carbon emissions are reduced by 34\% to 39\% when the natural gas carbon emission factor is half of the current one. The results denote that reducing the carbon emission factor of natural gas can be a very effective method of reducing carbon footprint.

The life cycle framework proposed in this study provided a reference to calculate the life cycle costs and carbon emissions of DES, and inspired designers to optimize the design and operation strategies comprehensively while achieving the goals of minimal life cycle cost and carbon emissions, which have significant practical engineering value. However, this model can only be applied to small-scale region and cannot be used for prefecture-level or national-level analysis. Therefore, further studies are still required for a more comprehensive conclusion, for example, the price elasticity of natural gas, biomass, and electricity, and the equity of carbon emissions.

\section{Nomenclature}

Sets and indices

$\begin{array}{ll}i \in I & \text { All facilities: GSHP, GB, BIO, CHP, COC, ABC, PV, HS, BT, CS } \\ j \in J & \text { Energy allocation facilities: GSHP, GB, BIO, CHP, COC, ABC } \\ k \in K & \text { Energy storage facilities: HS, BT, CS } \\ m \in M & \text { Energy carriers: grid, gas, bio } \\ t \in T & \text { Number of time steps } \\ t \in \bar{T} & \text { First time step of the day } \\ n \in N & \text { Number of clusters } \\ u \in U & \text { Number of buildings }\end{array}$

Continuous Parameters

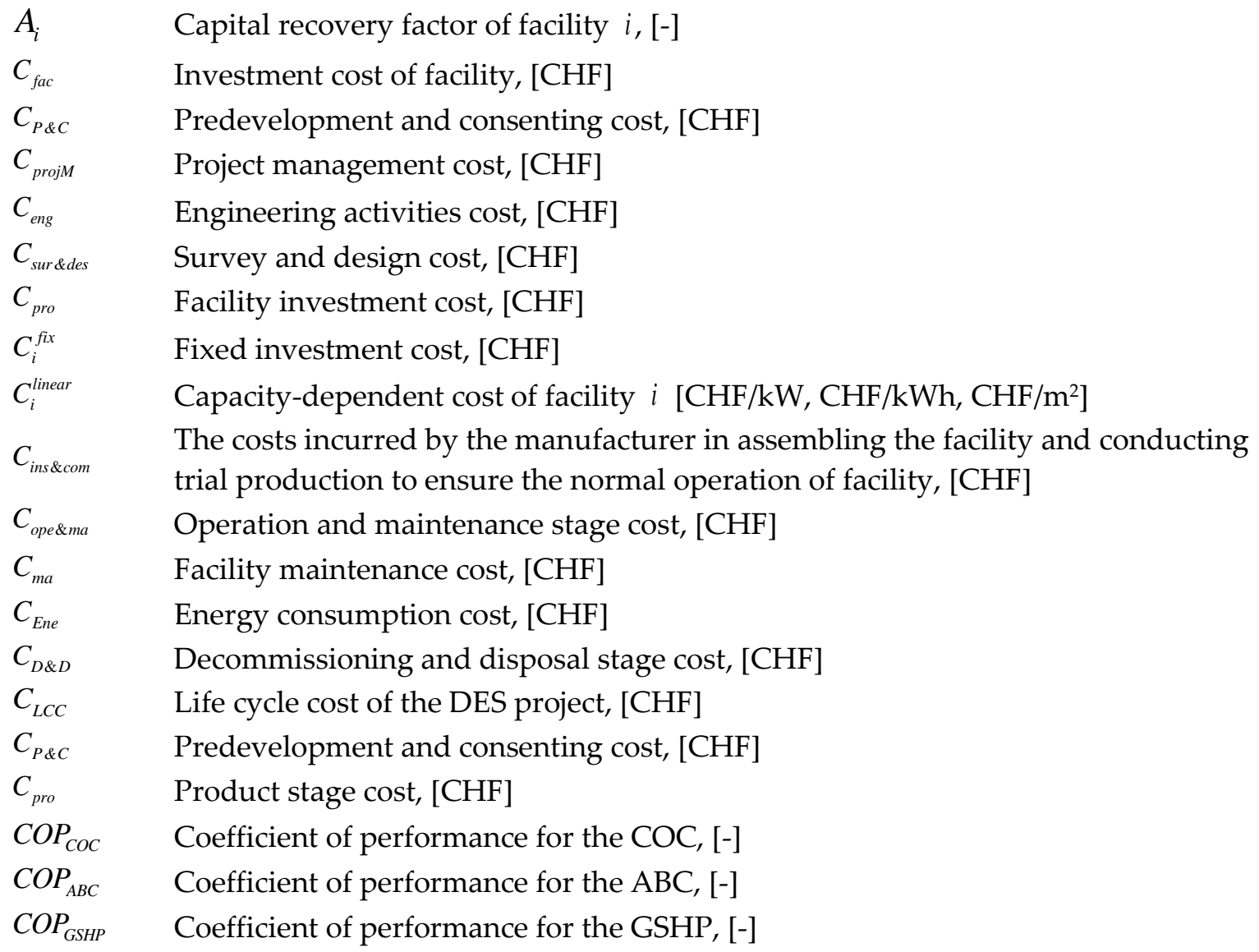




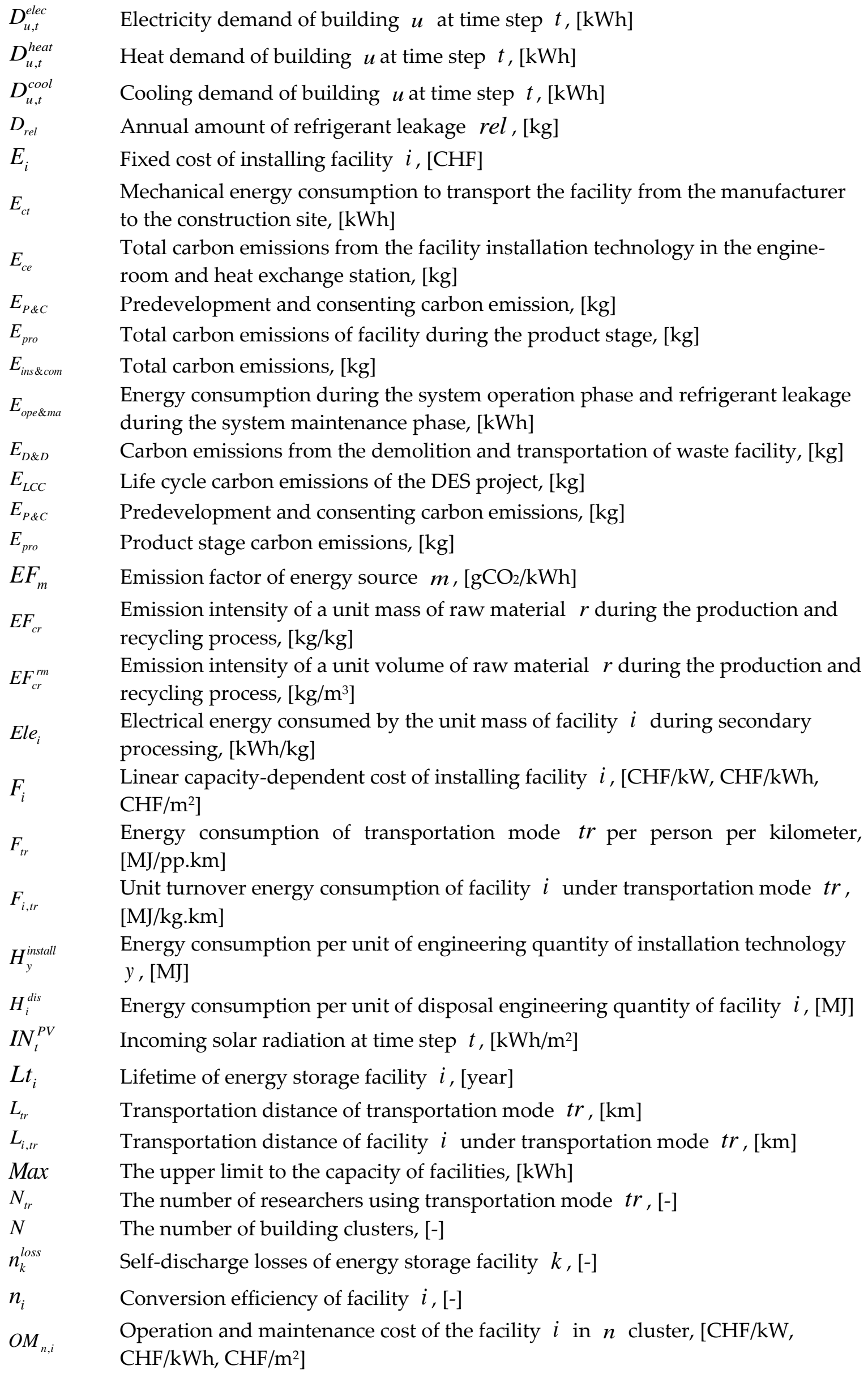




\begin{tabular}{|c|c|}
\hline$P_{t, m}$ & Price of energy carrier $m$ at time step $t,[\mathrm{CHF} / \mathrm{kWh}]$ \\
\hline$P V_{n}$ & Available capacity for PV panels in cluster $n,[\mathrm{kWh}]$ \\
\hline$Q_{i, r}$ & Mass or volume of raw material $r$ used in facility $i,\left[\mathrm{~kg}, \mathrm{~m}^{3}\right]$ \\
\hline$r$ & Discount rate, $[-]$ \\
\hline$R_{y}^{\text {install }}$ & $\begin{array}{l}\text { Engineering quantity of installation technology } y \text { in the engine-room or heat } \\
\text { exchange station, [-] }\end{array}$ \\
\hline$R_{n, i, t}$ & $\begin{array}{l}\text { Energy rate provided by the facility } i \text { at time step } t \text { in } n \text { cluster, }[\mathrm{kW}, \mathrm{kWh} \text {, } \\
\left.\mathrm{m}^{2}\right]\end{array}$ \\
\hline$R_{i}^{d i s}$ & $\begin{array}{l}\text { Disposal engineering quantity of facility } i \text { in the engine-room or heat exchange } \\
\text { station, [-] }\end{array}$ \\
\hline$S_{k}^{\max }$ & Maximum capacity for energy storage facility $k,[\mathrm{kWh}]$ \\
\hline$S_{u}^{r o o f}$ & Available roof area for installation of PV panels on building $u,\left[\mathrm{~m}^{2}\right]$ \\
\hline$T_{\text {ope\&ma }}$ & System operation period, [year] \\
\hline$T$ & One calendar year, [h] \\
\hline$w_{t}$ & Total number of time step $t$ in a typical day, [-] \\
\hline$\alpha_{\text {rel }}$ & Climate change potential of refrigerant $\mathrm{rel},[\mathrm{kgCO} / \mathrm{kg}]$ \\
\hline$\lambda_{t r}$ & $\begin{array}{l}\text { Carbon emissions generated by the unit fuel used for transportation mode } t r \\
{[\mathrm{~kg} / \mathrm{MJ}]}\end{array}$ \\
\hline$\lambda_{y}^{\text {install }}$ & $\begin{array}{l}\text { Carbon emissions generated by the unit fuel used for installation technology } y \\
{[\mathrm{~kg} / \mathrm{MJ}]}\end{array}$ \\
\hline$\lambda_{i}^{\text {dis }}$ & $\begin{array}{l}\text { Carbon emissions generated by the unit fuel used for demolishing facility } i \\
{[\mathrm{~kg} / \mathrm{MJ}]}\end{array}$ \\
\hline$\varepsilon_{r}$ & $\begin{array}{l}\text { Waste coefficient of raw material } r \text { due to loss during the production process, [- } \\
\text { ] }\end{array}$ \\
\hline$\delta$ & Recovery coefficient of raw material $r,[-]$ \\
\hline
\end{tabular}

Positive continuous variables

$W_{n, i} \quad$ Capacity of facility $i$ in cluster $n,[\mathrm{~kW}$ for conversion devices, $\mathrm{kWh}$ for storage devices, $\mathrm{m}^{2}$ for PV panels]

$C P_{n, t, m} \quad$ Consumption of energy carrier $m$ at time step $t$ in cluster $n,[\mathrm{kWh}]$

$M_{n, t, i} \quad$ Energy input to the converter $i$ at time step $t$ in cluster $n,[\mathrm{kWh}]$

$N_{n, t, k}^{c h} \quad$ Charging rate of energy storage facility $k$ at time step $t$ in cluster $n,[\mathrm{kWh}]$

$N_{n, t, k}^{d i s} \quad$ Discharging rate of energy storage facility $k$ at time step $t$ in cluster $n,[\mathrm{kWh}]$

$S_{n, t, k} \quad$ Energy stored in facility $k$ at time step $t$ in cluster $n,[\mathrm{kWh}]$

$W_{n, i} \quad$ Capacity of facility $i$ in cluster $n,[\mathrm{~kW}$ for conversion devices, $\mathrm{kWh}$ for storage devices, $\mathrm{m}^{2}$ for PV panels]

$C P_{n, t, m} \quad$ Consumption of energy carrier $m$ at time step $t$ in cluster $n,[\mathrm{kWh}]$

Binary variables

$B_{n, i} \quad$ If the facility $i$ is selected in cluster $n, B_{n, i}=1$. Otherwise, $B_{n, i}=0$.

$X_{n, u} \quad$ If the building $u$ belongs to the cluster $n, X_{n, u}=1$. Otherwise, $X_{n, u}=0$.

Acronyms

MOMP Multi-objective mathematical programming

GHG Greenhouse gas 


$\begin{array}{ll}\text { DES } & \text { Distributed energy system } \\ \text { GSHP } & \text { Ground-source heat pump } \\ \text { GB } & \text { Gas boiler } \\ \text { CHP } & \text { Gas-fired CHP engine } \\ \text { BIO } & \text { Biomass boiler } \\ \text { COC } & \text { Compression chiller } \\ \text { ABC } & \text { Absorption chiller } \\ \text { PV } & \text { PV panels } \\ \text { BT } & \text { Battery } \\ \text { HS } & \text { Heating storage } \\ \text { CS } & \text { Cooling storage }\end{array}$

\section{Acknowledgements}

This work was partially supported by the National Natural Science Foundation of China (51874325) and the Grant-in-Aid for Early-Career Scientists (19K15260) from the Japan Ministry of Education, Culture, Sports, Science and Technology.

\section{Reference}

Acha, S., Mariaud, A., Shah, N., Markides, C.N., 2018. Optimal design and operation of distributed low-carbon energy technologies in commercial buildings. Energy 142, 578-591.

Akorede, M.F., Hizam, H., Pouresmaeil, E., 2010. Distributed energy resources and benefits to the environment. Renewable and Sustainable Energy Reviews 14(2), 724-734.

Anastas, P.T., Zimmerman, J.B., 2003. Peer Reviewed: Design Through the 12 Principles of Green Engineering. Environmental Science \& Technology 37(5), 94A-101A.

Anastaselos, D., Oxizidis, S., Manoudis, A., Papadopoulos, A.M., 2016. Environmental performance of energy systems of residential buildings: Toward sustainable communities. Sustainable Cities and Society 20, 96-108.

Arcuri, P., Florio, G., Fragiacomo, P., 2007. A mixed integer programming model for optimal design of trigeneration in a hospital complex. Energy 32(8), 1430-1447.

Chau, C.K., Leung, T.M., Ng, W.Y., 2015. A review on Life Cycle Assessment, Life Cycle Energy Assessment and Life Cycle Carbon Emissions Assessment on buildings. Applied Energy 143, 395413.

de Wild-Scholten, M.J., 2013. Energy payback time and carbon footprint of commercial photovoltaic systems. Solar Energy Materials and Solar Cells 119, 296-305.

Di Somma, M., Yan, B., Bianco, N., Graditi, G., Luh, P.B., Mongibello, L., Naso, V., 2017. Multiobjective design optimization of distributed energy systems through cost and exergy assessments. Applied Energy 204, 1299-1316.

Duan, Z., Yan, Y., Yan, X., Liao, Q., Zhang, W., Liang, Y., Xia, T., 2017. An MILP Method for Design of Distributed Energy Resource System Considering Stochastic Energy Supply and Demand. Energies 11(1).

Edenhofer, O., Seyboth, K., 2013. Intergovernmental Panel on Climate Change (IPCC), in: Shogren, J.F. (Ed.) Encyclopedia of Energy, Natural Resource, and Environmental Economics. Elsevier, Waltham, pp. 48-56.

Esmaili, M., Amjady, N., Shayanfar, H.A., 2011. Multi-objective congestion management by modified augmented $\varepsilon$-constraint method. Applied Energy 88(3), 755-766. 
Fenner, A.E., Kibert, C.J., Woo, J., Morque, S., Razkenari, M., Hakim, H., Lu, X., 2018. The carbon footprint of buildings: A review of methodologies and applications. Renewable and Sustainable Energy Reviews 94, 1142-1152.

Fournier, E.D., Federico, F., Porse, E., Pincetl, S., 2019. Effects of building size growth on residential energy efficiency and conservation in California. Applied Energy 240, 446-452.

Gao, J., Kang, J., Zhang, C., Gang, W., 2018. Energy performance and operation characteristics of distributed energy systems with district cooling systems in subtropical areas under different control strategies. Energy 153, 849-860.

He, B.-J., Yang, L., Ye, M., 2014. Building energy efficiency in China rural areas: Situation, drawbacks, challenges, corresponding measures and policies. Sustainable Cities and Society 11, 7-15.

K, P., Govindarajan, U., K. Ramachandaramurthy, V., T, S.O.S., 2017. Multiple Criteria Decision Making (MCDM) Based Economic Analysis of Solar PV System with Respect to Performance Investigation for Indian Market. Sustainability 9(5).

Khan, M.W., Wang, J., Ma, M., Xiong, L., Li, P., Wu, F., 2019. Optimal energy management and control aspects of distributed microgrid using multi-agent systems. Sustainable Cities and Society $44,855-$ 870.

Khan, M.W., Wang, J., Xiong, L., Ma, M., 2018. Modelling and optimal management of distributed microgrid using multi-agent systems. Sustainable Cities and Society 41, 154-169.

Li, L., Mu, H., Li, N., Li, M., 2016. Economic and environmental optimization for distributed energy resource systems coupled with district energy networks. Energy 109, 947-960.

Li, Y., Liang, W., Tan, R., 2017. Optimal design of installation capacity and operation strategy for distributed energy system. Applied Thermal Engineering 125, 756-766.

Mavromatidis, G., Orehounig, K., Carmeliet, J., 2018. Uncertainty and global sensitivity analysis for the optimal design of distributed energy systems. Applied Energy 214, 219-238.

Mavrotas, G., 2009. Effective implementation of the $\varepsilon$-constraint method in Multi-Objective Mathematical Programming problems. Applied Mathematics and Computation 213(2), 455-465.

Nematchoua, M.K., Teller, J., Reiter, S., 2019. Statistical life cycle assessment of residential buildings in a temperate climate of northern part of Europe. Journal of Cleaner Production.

Ooka, R., Komamura, K., 2009. Optimal design method for building energy systems using genetic algorithms. Building and Environment 44(7), 1538-1544.

Padmanathan, K., Govindarajan, U., Ramachandaramurthy, V.K., Rajagopalan, A., Pachaivannan, N., Sowmmiya, U., Padmanaban, S., Holm-Nielsen, J.B., Xavier, S., Periasamy, S.K., 2019. A sociocultural study on solar photovoltaic energy system in India: Stratification and policy implication. Journal of Cleaner Production 216, 461-481.

Robati, M., Daly, D., Kokogiannakis, G., 2019. A method of uncertainty analysis for whole-life embodied carbon emissions (CO2-e) of building materials of a net-zero energy building in Australia. Journal of Cleaner Production 225, 541-553.

Sharma, A., Saxena, A., Sethi, M., Shree, V., Varun, 2011. Life cycle assessment of buildings: A review. Renewable and Sustainable Energy Reviews 15(1), 871-875.

Sim, J., Sim, J., 2016. The effect of new carbon emission reduction targets on an apartment building in South Korea. Energy and Buildings 127, 637-647.

Tan, X., Lai, H., Gu, B., Zeng, Y., Li, H., 2018. Carbon emission and abatement potential outlook in China's building sector through 2050. Energy Policy 118, 429-439.

Wang, B., Liang, Y., Zheng, T., Yuan, M., Zhang, H., 2018. Multi-objective site selection optimization of 
the gas-gathering station using NSGA-II. Process Safety and Environmental Protection 119, 350359.

Wrålsen, B., O'Born, R., Skaar, C., 2018. Life cycle assessment of an ambitious renovation of a Norwegian apartment building to nZEB standard. Energy and Buildings 177, 197-206.

Xing, X., Yan, Y., Zhang, H., Long, Y., Wang, Y., Liang, Y., 2019. Optimal design of distributed energy systems for industrial parks under gas shortage based on augmented $\varepsilon$-constraint method. Journal of Cleaner Production 218, 782-795.

Yan, Y., Zhang, H., Long, Y., Wang, Y., Liang, Y., Song, X., Yu, J.J.Q., 2019. Multi-objective design optimization of combined cooling, heating and power system for cruise ship application. Journal of Cleaner Production.

Yang, Y., Zhang, S., Xiao, Y., 2015. Optimal design of distributed energy resource systems coupled with energy distribution networks. Energy 85, 433-448.

Zhang, X., Lovati, M., Vigna, I., Widén, J., Han, M., Gal, C., Feng, T., 2018. A review of urban energy systems at building cluster level incorporating renewable-energy-source (RES) envelope solutions. Applied Energy 230, 1034-1056.

Zhu, Y., Tong, Q., Zeng, X., Yan, X., Li, Y., Huang, G., 2019. Optimal Design of a Distributed Energy System Using the Functional Interval Model That Allows Reduced Carbon Emissions in Guanzhong, a Rural Area of China. Sustainability 11(7). 